\title{
Towards a standard typology of endogenous landslide seismic sources
}

\author{
Floriane Provost ${ }^{1}$, Jean-Philippe Malet ${ }^{1}$, Clément Hibert ${ }^{1}$, Agnès Helmstetter $^{2}$, Mathilde Radiguet ${ }^{2}$, \\ David Amitrano ${ }^{2}$, Nadège Langet ${ }^{3}$, Eric Larose ${ }^{2}$, Clàudia Abancó ${ }^{4}$, Marcel Hürlimann ${ }^{5}$, \\ Thomas Lebourg $^{6}$, Clara Levy ${ }^{7}$, Gaëlle Le Roy ${ }^{2,8}$, Patrice Ulrich ${ }^{1}$, Maurin Vidal ${ }^{7}$, and Benjamin Vial ${ }^{2}$ \\ ${ }^{1}$ Institut de Physique du Globe de Strasbourg, CNRS UMR 7516, EOST/Université de Strasbourg, \\ 5 rue Descartes, 67084 Strasbourg CEDEX, France \\ ${ }^{2}$ Univ. Grenoble Alpes, Univ. Savoie Mont Blanc, CNRS, IRD, IFSTTAR, ISTerre, 38000 Grenoble, France \\ ${ }^{3}$ Norsar, Gunnar Randers Vei 15, 2007 Kjeller, Norway \\ ${ }^{4}$ Geological Hazards Prevention Unit, Institut Cartografic i Geologic de Catalunya, Parc de Montjuïc, \\ 08038 Barcelona, Spain \\ ${ }^{5}$ Departament of Civil and Environmental Engineering, UPC-BarcelonaTECH, C. Jordi Girona 1-3, \\ 08034 Barcelona, Spain \\ ${ }^{6}$ Géosciences Azur, CNRS UMR 7329, OCA/Université de Nice, 250 rue Albert Einstein, \\ 06905 Sophia-Antipolis CEDEX, France \\ ${ }^{7}$ BRGM, Avenue C. Guillemin, 45100 Orléans, France \\ ${ }^{8}$ Géolithe, Crolles, France \\ Correspondence: Floriane Provost (f.provost@unistra.fr)
}

Received: 8 March 2018 - Discussion started: 21 March 2018

Revised: 30 September 2018 - Accepted: 12 October 2018 - Published: 16 November 2018

\begin{abstract}
The objective of this work is to propose a standard classification of seismic signals generated by gravitational processes and detected at close distances $(<1 \mathrm{~km})$. We review the studies where seismic instruments have been installed on unstable slopes and discuss the choice of the seismic instruments and the network geometries. Seismic observations acquired at 13 unstable slopes are analyzed in order to construct the proposed typology. The selected slopes are affected by various landslide types (slide, fall, topple and flow) triggered in various material (from unconsolidated soils to consolidated rocks). We investigate high-frequency bands $(>1 \mathrm{~Hz})$ where most of the seismic energy is recorded at the $1 \mathrm{~km}$ sensor to source distances. Several signal properties (duration, spectral content and spectrogram shape) are used to describe the sources. We observe that similar gravitational processes generate similar signals at different slopes. Three main classes can be differentiated mainly from the length of the signals, the number of peaks and the duration of the autocorrelation. The classes are the "slopequake" class, which corresponds to sources potentially occurring within the landslide body; the "rockfall" class, which corresponds to signals generated by rock block impacts; and the "granular flow" class, which corresponds to signals generated by wet or dry debris/rock flows. Subclasses are further proposed to differentiate specific signal properties (frequency content, resonance, precursory signal). The signal properties of each class and subclass are described and several signals of the same class recorded at different slopes are presented. Their potential origins are discussed. The typology aims to serve as a standard for further comparisons of the endogenous microseismicity recorded on landslides.
\end{abstract}




\section{Introduction}

Seismology can be used to record (remotely and in a noninvasive way) ground deformation processes and to measure stress-strain conditions through the hydromechanical interactions occurring in the media. Seismology is widely used to understand the physical processes taking place on tectonic faults or volcanoes, to investigate fluid reservoir circulation, and more recently to analyze the dynamics of Earth surface processes such as glaciers (Podolskiy and Walter, 2016), snow avalanches (Leprettre et al., 1996; Sabot et al., 1998; Surin et al., 2000; Lacroix et al., 2011; Pérez-Guillén et al., 2016) and landslides (Deparis et al., 2008; Ekström and Stark, 2013; Gomberg et al., 1995; Rouse et al., 1991). In this manuscript, the term landslide describes a wide variety of processes resulting from the downslope movement of slope-forming materials by falling, toppling, sliding or flowing mechanisms (Hungr et al., 2014). Thus, landslides cover a large range of deformation processes, that can be differentiated in terms of sizes and volumes (smaller than $1 \mathrm{~m}^{3}$ up to more than $\left.10^{7} \mathrm{~m}^{3}\right)$, in terms of displacement rates $\left(\mathrm{mm} \mathrm{yr}^{-1}\right.$ to $\mathrm{m} \mathrm{s}^{-1}$ ), and in terms of mobilized material (hard or soft rocks, debris, poorly consolidated soils, and artificial fills).

With the increasing number of seismic sensors deployed worldwide and the development of automatic seismological processing chains, the construction of landslide catalogs using seismology is now possible, especially at the regional scale (e.g., Switzerland; Hammer et al., 2013; Dammeier et al., 2016 or France; Deparis et al., 2008). However, the forecast of a particular landslide rupture or acceleration is still challenging at the slope scale, which is the focus of this work. In the 1960s, Cadman and Goodman (1967) observed an increase in acoustic emissions (AEs) generated by slopes tilted towards failure at both laboratory and field scales. AEs are high-frequency $(10-1000 \mathrm{kHz})$ body waves generated by the release of strain energy through grain rearrangement (Michlmayr et al., 2012). Further studies confirmed these results for several slopes (Rouse et al., 1991; Smith et al., 2014; Dixon et al., 2015, 2018), where correlations between AE, surface displacement and heavy rainfall were documented. AEs record deep deformation processes before signs of displacement are identifiable at the surface. However, AEs are rapidly attenuated with the distance to the sources. The location of the sensors and the type of waveguide are also critical to capture the slope behavior. Recent developments of fiber optic distributed acoustic systems (FO-DAS) offer the opportunity to overcome attenuation limitations and deploy measures over long distances (Michlmayr et al., 2017). More recently, several studies focused on the analysis of the microseismicity (MS) observed on unstable slopes. MS studies analyze the seismic waves generated by the release of strain energy in the ground at a larger scale than the grainto-grain interactions in the frequency range of 1 to $500 \mathrm{~Hz}$. The method offers the opportunity to remotely record the spatial distribution of the deformation through time (Mc-
Cann and Forster, 1990; BRGM, 1995) and is less sensitive to attenuation than AE methods. Gomberg et al. (1995) installed seismometers on the Slumgullion slow-moving landslide (Colorado, USA) in order to understand the mechanical processes taking place during landslide deformation. Further studies used the same method for several slope configurations (hard or soft rocks, soils, very slow to rapid movements) but also investigated the possible links between the displacement rate and the seismic energy release (Spillmann et al., 2007; Helmstetter and Garambois, 2010; Walter et al., 2012, 2013b; Tonnellier et al., 2013). Helmstetter and Garambois (2010) correlated the seismic response of the Séchilienne rockslide with the surface displacement rate and the rainfall amount. The analysis of the seismic waves generated by landslides allows for monitoring spatiotemporal changes in the stress-strain field in the material from the scale of microscopic internal damage (Dixon et al., 2003; Michlmayr et al., 2012; Smith et al., 2017) to the initiation (e.g., pre-failure) of large ruptures (Amitrano et al., 2005; Yamada et al., 2016b; Poli, 2017; Schöpa et al., 2018). Both the failure and surface processes (e.g., rockfall, debris flow) generate seismic waves. Physical properties (mass, bulk momentum, velocity, trajectory) of the landslide can be inferred from the analysis of the seismic signals (Kanamori et al., 1984; Brodsky et al., 2003; Lacroix and Helmstetter, 2011; Ekström and Stark, 2013; Tang et al., 2015; Hibert et al., 2014a; Levy et al., 2015). On clayey landslides, drops in shear-wave velocity have been observed before acceleration episodes. This shear-wave variation through time has been documented using noise correlation techniques for laboratory experiments (Mainsant et al., 2012b), and for a few cases in the field at Pont Bourquin landslide (Switzerland; Mainsant et al., 2012a), at Harmaliére landslide (France; Bièvre et al., 2017) and at Just-Tegoborze landslide (Poland; Harba and Pilecki, 2017). Precursory seismic signals are also expected and documented before large failures. Precursory increase in microseismic activity (in terms of event rates and/or average amplitudes) has been observed first before the fall of a coastal cliff (Mesnil-Val, France; Amitrano et al., 2005) and was interpreted as the propagation of a fracture. More recently, repeating events have been detected before the Rausu landslide (Japan; Yamada et al., 2016b) and the Nuugaatsiaq landslide (Greenland; Poli, 2017). These events are likely associated with the repeated failure of asperities surrounded by aseismic slip, driven by the acceleration of the slope displacement during the nucleation phase of the landslide rupture. Schöpa et al. (2018) recorded harmonic tremors that started $30 \mathrm{~min}$ before the failure of the Askja caldera landslide (Iceland) with temporal fluctuations of resonance frequency around $2.5 \mathrm{~Hz}$. This complex tremor signal was interpreted as repeating stick-slip events with very short recurrence times (less than $1 \mathrm{~s}$ ) producing a continuous signal. However, the characterization of the size of the asperity and the velocity of the ruptures associated with these precursory signals are difficult to invert mostly because of the lack of a dense seismic 
network at close proximity to the slope instability (Schöpa et al., 2018). Therefore, the monitoring of endogenous MS may represent a promising approach, especially with the advent of robust, cheaper and portable seismic sensors and digitizers. It is now possible to install dense sensor networks close to the unstable slopes and record low amplitude signals in broad frequency bands. A wide variety of unstable slopes are currently monitored (i.e., through permanent or campaign installations) with seismic networks of different sizes and instruments (Table 1).

Understanding the possible mechanisms generating these seismic signals needs to be achieved. The discrimination of the endogenous landslide seismic signals is difficult and needs to be established. The objective of this paper is thus to propose a typology of the landslide microseismic signals recorded in the field. The proposed typology is based on the analysis of observations from 13 monitored sites. The typology includes all of the seismic sources recorded at near distances $(<1 \mathrm{~km})$ and in the frequency range of MS studies $(1-500 \mathrm{~Hz})$, and generated by landslides (1) developed in hard or soft rocks and soils, and (2) characterized by fragile (i.e., rupture) and ductile (i.e., viscous) deformation mechanisms.

In our work, we first discuss all the physical processes that occur on landslides and may generate seismic signals. We further present the available seismic sensors, the most commonly used network geometry and the instrumented sites. Then we establish a classification scheme of the landslide seismic signals from relevant signal features based on the analysis of the datasets of 13 sites. We further discuss the perspectives and remaining challenges of monitoring landslide deformation with MS approaches. The seismic signals associated with very large rock/debris avalanches and slides observed at regional distances are out of the scope of this work.

\section{Description of landslide endogenous seismic sources}

This section describes the possible hydromechanical processes observed on landslides that are susceptible to generate seismic sources. We present the conditions controlling their occurrences (type of material, topography), their sizes and their mechanical properties.

\subsection{Fracture-related sources}

The term fracture denominates any discontinuous surface observed in consolidated media and originating from the formation of the rocks (i.e., joint) or the action of tectonic (i.e., schistosity), gravitational or hydraulic loads. In the case of slow-moving landslides, the propagation of the material also creates fractures on the edge and at the base of the moving material. Fractures occur in all types of materials at different scales ranging from grain rupture to metric faults. The term fissure is sometimes used to describe fractures affecting the surface of the ground and for fractures affecting poorly consolidated material. We here include all these surface discontinuities under the general term "fracture". Fractures are generated in three basic modes (I: opening, II: sliding and III: tearing) depending on the movement of the medium on the sides of the fracture plane. They result from either brittle failure of the media or from desiccation effects forming polygonal failures during soil drying. On landslides, most of the fractures occur in a tensile mode because of the low tensile toughness of the landslide material and the shallow depth (Stumpf et al., 2013). The formation of fractures can also be generated in depth by progressive degradation of the rock through ground shaking and/or through weathering and longterm damage due to gravitational load. At the base and on the edges of the landslide, the movement is assumed to develop fractures in shear mode, creating sliding surfaces. Shearing on the fracture plane and tensile fracture opening/closing generate seismic signals. Shearing takes place at different scales ranging from earthquakes on tectonic plates to grain friction and generates a variety of seismic signals (Zigone et al., 2011). The unstable regime leads to stick-slip behavior where the stress is regularly and suddenly released generating impulsive seismic events. Tremor-like signals or isolated impulsive or emergent events are also generated during plate motions. A variety of signals are observed during glacier motion. Deep icequakes are usually associated with basal motion (Winberry et al., 2011; Pratt et al., 2014; Helmstetter et al., 2015a, b; Roeoesli et al., 2016a; Podolskiy and Walter, 2016). Tremor-like signals are also recorded during glacier motion (Lipovsky and Dunham, 2016). They are characterized by long duration signals of low amplitudes with no clear phase onsets. They are associated with repetitive stick-slip events on the fracture plane. Tensile fracture opening/closing generate similar signals on glaciers at the surface and at depth (Walter et al., 2013a; Helmstetter et al., 2015b; Podolskiy and Walter, 2016). Knowledge of the focal mechanism and location of the source allows differentiation between the tensile and shear mechanism.

\subsection{Topple and fall related sources}

On vertical to subvertical slopes, mass movement occurs as the topple of rock columns or as the free fall (and possibly bouncing and rolling) of rocky blocks (Hungr et al., 2014). In the case of toppling, the movement starts with a slow rotation of the rock blocks under the effects of water infiltration or ground shaking and ends with the free fall of larger blocks. Rockfalls, during the propagation phase, impact the ground at some location along their trajectory. These impacts generate seismic waves that can be recorded remotely by seismometers. The range of rockfall volumes can be very large, varying from less than one cubic meter to thousands of cubic meters. 
Table 1. Table of the instrumented sites. The bolded names correspond to the sites investigated in the present paper to establish the typology.

\begin{tabular}{|c|c|c|c|c|c|c|c|}
\hline Number & Site & Location & Type & Material & Sensor & Duration & Reference/research group \\
\hline 1 & Randa & Switzerland & Slide & Hard rock & G & $\mathrm{SC}$ & Spillmann et al. (2007) \\
\hline 2 & Séchilienne & France & Slide & Hard rock & $\mathrm{G}, \mathrm{SP}$ & $\mathrm{P}$ & $\begin{array}{l}\text { RESIF/OMIV (2015); Helmstetter and Garambois (2010); } \\
\text { Lacroix and Helmstetter (2011) }\end{array}$ \\
\hline 3 & La Clapière & France & Slide & Hard rock & $\mathrm{SP}(?)$ & $\mathrm{P}$ & RESIF/OMIV (2015); Palis et al. (2017) \\
\hline 4 & Aaknes & Norway & Slide & Hard rock & $\mathrm{G}, \mathrm{BB}$ & $\mathrm{P}$ & Roth et al. (2008) \\
\hline 5 & Peschiera Spring & Italy & Slide & Hard rock & A & $\mathrm{SC}$ & Lenti et al. (2013) \\
\hline 6 & Gradenbach & Austria & Slide & Hard rock & SP & $\mathrm{P}(?)$ & Brückl et al. (2013) \\
\hline 7 & Alestch-Moosfluh & Switzerland & Slide & Hard rock & BB & $\mathrm{P}$ & Helmstetter et al. (2017b); Manconi and Coviello (2018) \\
\hline 8 & Assisi & Italy & Slide & Hard rock & SP & $\mathrm{SC}$ & Lotti et al. (2015) \\
\hline 9 & Akatami landslide & Japan & Slide & Hard rock & (?) & (?) & - \\
\hline 10 & Akkeshi landslide & Japan & Slide & Hard rock & SP & $\mathrm{P}$ & Doi et al. (2015) \\
\hline 11 & Rausu landslide & Japan & Slide & Hard rock & BB & $\mathrm{P}$ & Yamada et al. (2016a) \\
\hline 12 & Fergurson slide/Mercel River & USA/California & Slide & Hard rock & (?) & (?) & Harp et al. (2008) \\
\hline 13 & Turtle Mountain - Frank slide & Canada & Slide & Hard rock & $\mathrm{G}$ & $\mathrm{P}$ & Chen et al. (2005) \\
\hline 14 & Aiguilles-Pas de l'Ours & France & Slide & Soft rock/Earth & $\mathrm{BB}$ & $\mathrm{SC}$ & RESIF/OMIV (2015) \\
\hline 15 & Harmalière & France & Slide & Soft-rock & SP, BB & $\mathrm{P}$ & Bièvre et al. (2017) \\
\hline 16 & Utiku & New Zealand & Slide & Soft rock/Earth & (?) & $\mathrm{P}$ & Voisin et al. (2013) \\
\hline 17 & Villerville & France & Slide & Soft rock/mud & $\mathrm{BB}$ & $\mathrm{SC}, \mathrm{P}$ & RESIF/OMIV (2015) \\
\hline 18 & Super-Sauze & France & Slide & Soft rock/mud & SP & $\mathrm{P}, \mathrm{RC}$ & $\begin{array}{l}\text { RESIF/OMIV (2015); Walter et al. (2012); Tonnellier et al. } \\
\text { (2013); Vouillamoz et al. (2018) }\end{array}$ \\
\hline 19 & Pont Bourquin & Switzerland & Slide & Mud & $\mathrm{SP}(?)$ & $\mathrm{P}$ & Mainsant et al. (2012a); Larose et al. (2015) \\
\hline 20 & Valoria & Italy & Slide & Mud & SP & $\mathrm{SC}$ & Tonnellier et al. (2013) \\
\hline 21 & Pechgraben & Austria & Slide & Mud & SP, BB & $\mathrm{RC}$ & Vouillamoz et al. (2018) \\
\hline 22 & US highway $50, \mathrm{CA}$ & USA & Slide & Earth & $\mathrm{G}$ & $\mathrm{P}$ & USGS (https://landslides.usgs.gov/monitoring/) \\
\hline 23 & Slumgullion & USA & Slide & Earth & $\mathrm{G}$ & $\mathrm{RC}$ & Gomberg et al. $(1995,2011)$ \\
\hline 24 & Millcoma Meander, Oregon & USA & Slide & Earth & G & $\mathrm{P}$ & USGS (https://landslides.usgs.gov/monitoring/) \\
\hline 25 & Xishancun & China & Slide & Earth & BB & $\mathrm{SC}$ & - \\
\hline 26 & Chambon Tunnel & France & Slide & Earth & SP & $\mathrm{P}$ & - \\
\hline 27 & Maca & Peru & Slide & Soft rock/Earth & SP & $\mathrm{P}(?)$ & Larose et al. (2017) \\
\hline 28 & Heumoes & Germany & Slide & Soft rock/Earth & SP & $\mathrm{RC}$ & Walter et al. (2011) \\
\hline 29 & Mission Peak landslide & USA/California & Slide & Soft rock/Earth & BB & $\mathrm{P}$ & Hartzell et al. (2017) \\
\hline 30 & Char d'Osset & France & Slide, Fall & Soft rock/mud & & & - \\
\hline 31 & Mesnil-Val & France & Fall & Hard rock & G & $\mathrm{SC}$ & Amitrano et al. (2005); Senfaute et al. (2009) \\
\hline 32 & North Yorkshire coast & United Kingdom & Fall & Hard rock & BB & $\mathrm{P}$ & Norman et al. (2013) \\
\hline 33 & Matterhorn & Italy & Fall & Hard rock & $\mathrm{G}$ & RC & Amitrano et al. (2010); Occhiena et al. (2012) \\
\hline 34 & Madonna del sasso & Italy & Fall & Hard rock & SP & $\mathrm{P}(?)$ & Colombero et al. (2018) \\
\hline 35 & Chamousset & France & Fall & Hard rock & SH & $\mathrm{RC}$ & Lévy et al. (2010); Bottelin et al. (2013b) \\
\hline 36 & Mont-Granier & France & Fall & Hard rock & $\mathrm{BB}$ & $\mathrm{P}$ & - \\
\hline 37 & Les Arches & France & Fall & Hard rock & SP & $\mathrm{P}(?)$ & Bottelin et al. (2013a, b) \\
\hline 38 & La Praz & France & Fall & Hard rock & SP & $\mathrm{P}(?)$ & Bottelin et al. (2013b) \\
\hline 39 & Rubi & France & Fall & Hard rock & SP & $\mathrm{P}(?)$ & Bottelin et al. (2013b) \\
\hline 40 & La Suche & Switzerland & Fall & Hard rock & SP & $\mathrm{P}(?)$ & Bottelin et al. (2013b) \\
\hline 41 & St. Eynard & France & Fall & Hard rock & SP & $\mathrm{P}(?)$ & Le Roy et al. $(2017,2018)$ \\
\hline 42 & Cap d'Ailly & France & Fall & Hard rock & & & 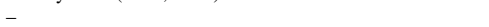 \\
\hline 43 & Lauterbrunnen valley & Switzerland & Fall & Hard rock & BB & $\mathrm{SC}$ & Dietze et al. (2017a, b) \\
\hline 44 & Three Brothers & USA & Fall & Hard rock & SP & $\mathrm{SC}$ & Zimmer and Sitar (2015) \\
\hline 45 & Mount Néron & France & Fall (triggered) & Hard rock & BB & $\mathrm{SC}$ & Bottelin et al. (2014) \\
\hline 46 & Riou Bourdoux & France & Fall (triggered) & Hard rock & $\mathrm{SP}, \mathrm{BB}$ & SC & Hibert et al. (2017a) \\
\hline 47 & Montserrat & Spain & Fall (triggered) & Hard rock & SP & $\mathrm{SC}$ & Vilajosana et al. (2008) \\
\hline 48 & Piton de la Fournaise & France & Fall, flow & Volcanic rock & $\mathrm{BB}$ & $\mathrm{P}$ & $\begin{array}{l}\text { OPVF/IPGP, Hibert et al. (2011, 2014a); Levy et al. (2015); } \\
\text { Hibert et al. (2017c) }\end{array}$ \\
\hline 49 & Bolungavík - Oshlíðslope & Iceland & Fall, flow & Hard rock & A & $\mathrm{P}$ & Bessason et al. (2007) \\
\hline 50 & Rebaixader & Spain & Flow & Debris & $\mathrm{G}$ & $\mathrm{P}$ & $\begin{array}{l}\text { Abancó et al. (2012, 2014); Hürlimann et al. (2014); Arat- } \\
\text { tano et al. (2014) }\end{array}$ \\
\hline 51 & Manival torrent & France & Flow & Debris & $\mathrm{G}$ & $\mathrm{P}$ & Navratil et al. (2012) \\
\hline 52 & Réal torrent & France & Flow & Debris & G & $\mathrm{P}$ & Navratil et al. (2012); Coviello et al. (2015) \\
\hline 53 & Marderello torrent & Italy & Flow & Debris & $\mathrm{G}$ & $\mathrm{P}$ & Arattano et al. (2016) \\
\hline 54 & Acquabona torrent & Italy & Flow & Debris & G & $\mathrm{P}(?)$ & Berti et al. (2000); Galgaro et al. (2005) \\
\hline 55 & Moscardo torrent & Italy & Flow & Debris & SP & $\mathrm{P}$ & Arattano and Moia (1999) \\
\hline 56 & Gadria torrent & Italy & Flow & Debris & $\mathrm{G}$ & $\mathrm{P}$ & Arattano et al. (2016) \\
\hline 57 & Mt. Yakedake volcano - Kamikamihorizawa Creek & Japan & Flow & Debris & & & Suwa et al. (2009) \\
\hline 58 & Lattenbach torrent & Austria & Flow & Debris & $\mathrm{G}$ & $\mathrm{P}(?)$ & Schimmel and Hübl (2016); Kogelnig et al. (2014) \\
\hline 59 & Illgraben torrent & Switzerland & Flow & Debris & $\mathrm{G}$ & $\mathrm{P}$ & Burtin et al. (2014); Walter et al. (2017) \\
\hline 60 & Farstrine torrent & Austria & Flow & Debris & $\mathrm{G}$ & $\mathrm{P}(?)$ & Schimmel and Hübl (2016) \\
\hline 61 & Wartschenbach torrent & Austria & Flow & Debris & $\mathrm{G}$ & $\mathrm{P}(?)$ & Schimmel and Hübl (2016) \\
\hline 62 & Dristenau torrent & Austria & Flow & Debris & $\mathrm{G}$ & $\mathrm{P}(?)$ & Schimmel and Hübl (2016) \\
\hline 63 & Shenmu creek & Taiwan & Flow & Debris & G & $\mathrm{P}$ & Yin et al. (2011) \\
\hline 64 & Ai-Yu-Zi creek & Taiwan & Flow & Debris & G & $\mathrm{P}$ & Huang et al. (2007) \\
\hline 65 & Fong-Ciou creek & Taiwan & Flow & Debris & G & $\mathrm{P}$ & Huang et al. (2007) \\
\hline 66 & Chenyoulan creek & Taiwan & Flow & Debris & G & $\mathrm{SC}$ & Burtin et al. (2013) \\
\hline 67 & Mt. Sakurajima Volcano - Nojiri Torrent & Japan & Flow & Debris & $\mathrm{G}$ & $\mathrm{P}$ & Itakura et al. (2000) \\
\hline 68 & Mount Pinatubo & Philippines & Flow & Debris & G & $\mathrm{P}$ & Marcial et al. (1996) \\
\hline 69 & Colima volcano & Mexico & Flow & Debris & LP & $\mathrm{P}$ & Zobin et al. (2009); Vázquez et al. (2016) \\
\hline 70 & Merapi volcano & Indonesia & Flow & Debris & $\mathrm{G}$ & $\mathrm{P}$ & Lavigne et al. (2000) \\
\hline 71 & Nevado del Huila volcano & Colombia & Flow & Debris & $\mathrm{G}$ & $\mathrm{P}$ ? & Worni et al. (2012) \\
\hline 72 & Cotopaxi volcano & Ecuador & Flow & Debris & BB & $\mathrm{P}$ & Kumagai et al. (2009) \\
\hline 73 & Mount Ruapehu & New-Zeland & Flow & Debris & $\mathrm{BB}$ & $\mathrm{P}$ & Lube et al. (2012) \\
\hline 74 & Sawatch Range, Colorado & USA & Flow & Debris & $\mathrm{G}$ & $\mathrm{P}$ & Kean et al. (2015) \\
\hline
\end{tabular}

G: geophone $(f=[0.1-10] \mathrm{kHz})$; SP: short-Period $(f=[0.1-100] \mathrm{Hz})$; BB: broadband $\left(f=\left[10^{-2}-100\right] \mathrm{Hz}\right)$; A: accelerometer; P: permanent monitoring; RC: repetitive campaigns; SC: single campaign. OPVF/IPGP: volcanological observatory of the Piton de la Fournaise/Institut de Physique du Globe de Paris. USGS: United States Geological Survey. 


\subsection{Mass-flow-related sources}

Mass flows gather different run-out processes of debris or of a mixture of water and debris. They cover a large range of volumes from large rock avalanches of several millions of cubic meters to small (hundreds of cubic meters) debris falls and flows (Hungr et al., 2001). They can occur in wet or dry conditions. The contacts of the rock/debris fragments with the bedrock and in the mass flow generate seismic radiations (Suriñach et al., 2001; Burtin et al., 2009; Schneider et al., 2010; Hibert et al., 2011; Abancó et al., 2012; Burtin et al., 2013; Levy et al., 2015; Kean et al., 2015; Vázquez et al., 2016; Hibert et al., 2017b). The seismic signal is hence a combination of grain contacts within the granular flow and of grain-to-ground surface contacts and hence generate a complex seismic signal.

\subsection{Fluid-related sources}

Hydrological forcing (e.g., precipitation, snowmelt) is one of the most common landslide triggers. The presence of fracture networks, water pipes and the heterogeneity of the rock/soil media result in the development of preferential water flow paths (Richards and Reddy, 2007; Hencher, 2010). These preferential flows induced local saturated area where the increase in pore water pressure may destabilize shallow or deep shear surfaces. In soils, the dissolution of material into finer granular debris creates weak zones prone to collapse either by suffusion (i.e., non cohesive material wash out under mechanical action) or by dispersion (i.e., chemical dissolution of fractured clay soils; Richards, Jones, 1981). In rocks, pipes may develop by erosion. In these saturated fracture networks, hydraulic fracturing can occur creating earthquakes and harmonic tremors related to flow migration in the fractures (Chouet, 1988; Benson et al., 2008; Tary et al., 2014a, b; Derode et al., 2015; Helmstetter et al., 2015b).

\section{Landslide seismic investigation}

\subsection{Sensors used in landslide monitoring}

Body and surface mechanical waves may be generated by the sources described in Sect. 2. Body waves (primary - P, secondary $-S$ ) radiate inside the media. $P$ waves shake the ground in the same direction they propagate while $S$ waves shake the ground perpendicularly to their propagation direction. Surface waves only travel along the surface of the ground and their velocity, frequency content and intensity change with the depth of propagation. Acoustic waves can be generated by the conversion of body waves at the surface. These waves travel in the air at a velocity of about $340 \mathrm{~m} \mathrm{~s}^{-1}$, slightly varying with temperature and air pressure. Acoustic waves are often generated by anthropogenic or atmospheric sources (gun shots, explosions, storms, etc.), but can also be generated by rockfalls, debris flows or shallow fracture events. All these mechanical waves are subject to attenuation with the travel distance; the high-frequency waves are attenuated faster than the low-frequency waves. The relatively low energy released by the landslide-related sources makes the choice of seismic instruments to deploy very important. Four types of instruments are used to record ground motion for different frequency ranges and sensitivities. For landslide monitoring, short-period (SP) seismometers and geophones, broadband (BB) seismometers, accelerometers and AE sensors are commonly installed in the field.

- Broadband seismometers are force-balanced sensors with a very low corner frequency $(<0.01 \mathrm{~Hz})$ that can record the ground motion with a flat response in a large frequency range $[0.01-25] \mathrm{Hz}$. They require a careful mass calibration during their installation and are sensitive to temperature and pressure variations. They are mostly used to record very weak ground motion and ambient noise;

- SP seismometers are passive or force-balanced instruments with a high corner frequency $(>1 \mathrm{~Hz})$. They measure the velocity of the ground with high sensitivity and a flat response in the $[1-100] \mathrm{Hz}$ frequency band. They are recommended for volcanic and glacier monitoring among other applications. They are less sensitive to air temperature and pressure variations and do not require mass calibration. They are hence particularly suitable for landslide monitoring. Geophones are similar to SP seismometers but usually cover higher frequencies [1-600] Hz with lower sensitivity. They are mainly used for active seismic campaigns but may also be installed for the same purposes as SP seismometers;

- Accelerometers are strong motion sensors able to record high amplitudes and high-frequency seismic waves. They can resolve accelerations in the frequency bands from 0.1 to $10 \mathrm{kHz}$. The response of the sensor is proportional to ground acceleration for all frequencies (there is no corner frequency). But the noise level is important for low frequencies and the sensitivity is not as good as for velocimeters. They are used to record strong ground motion in particular when installed close to epicenters $(<100 \mathrm{~km})$ of large earthquakes where seismometers usually saturate. For landslides, they are usually used as inclinometers;

- AE sensors can record ground vibrations at very high frequencies $(10-10 \mathrm{MHz})$ and low amplitudes. There are two types of AE sensors: the first type is very sensitive to a narrow frequency band only, while the second type is sensitive to a broader frequency band (Michlmayr et al., 2012). In the field, a waveguide is often installed together with AE sensors in order to counteract the attenuation of the signal. They are used in combination with accelerometers for structural monitoring and for laboratory experiments (e.g., loading, shear, 
flume tests) and can be used on landslides to monitor very low magnitude sources at the grain-to-grain interactions (Dixon et al., 2003; Michlmayr et al., 2012; Smith et al., 2017);

- In addition, microphones or infrasound sensors can be useful to detect, locate and classify landslides seismic signals (Kogelnig et al., 2014; Schimmel and Hübl, 2016; Helmstetter and Janex, 2017). The detection of acoustic waves and body waves at one point, because they propagate at different velocities, can be used to estimate the distance from the source. The relative amplitude of seismic and acoustic waves can also provide information on the depth of the source, because shallow sources generate more acoustic waves than deeper ones.

It must be noted that $\mathrm{AE}$ sensors only record AEs generated at very high frequencies $(>10 \mathrm{kHz})$ and consequently are very sensitive to attenuation. Indeed, attenuation factor $\mathrm{Q}$ is estimated to range between $10^{-2}$ and $10^{1} \mathrm{~dB} \mathrm{~cm}^{-1}$ (Michlmayr et al., 2012). Even with a waveguide, they must be collocated with the cracks or the sliding surfaces observed on the slope (Dixon et al., 2015). BB and SP seismometers and geophones record seismic signals in the common band of $10^{0}-10^{2} \mathrm{~Hz}$ and hence offer a solution to monitor more distant sources. The detection of a seismic source by MS sensors depends on the seismic energy released by the source, the sensor to the source distance and the attenuation of the media. Installation of MS sensors at the proximity of the geomorphological features of interest (e.g., scarp, faults, sliding surfaces, superficial crack networks, etc.) optimize the detection of the seismic signals generated by those processes but distant sources $(>1 \mathrm{~m})$ can also be recorded by MS sensors. The latter do not need to be colocated with the geomorphological features of interest. After correcting the sensor response, the signals generated by these sensors can be analyzed and compared in their common frequency range. Installation of BB seismometers can complete SP networks and enable us to investigate the low-frequency signals generated by the slope, while geophones are more adapted to explore very-high-frequency content $(>100 \mathrm{~Hz})$. Dense networks of the latter instruments are recommended to investigate the seismicity induced by landslide deformation while the installation of one unique BB seismometer is enough to investigate the low-frequency radiations of the landslide.

\subsection{Network geometry}

Several network configurations have been tested in different studies. It must be noted that the network geometry in the case of landslides is constrained by the site configuration. Indeed, the maintenance of seismic sensors may be very challenging when installed on the moving parts of the landslide; therefore, an installation on the most stable parts of the landslide or at its vicinity is often preferred for permanent monitoring (Spillmann et al., 2007; Helmstetter and Garambois,
2010; Walter et al., 2017). During field campaigns, maintenance of sensors installed on the unstable slopes is possible and often realized (Gomberg et al., 2011; Walter et al., 2012; Tonnellier et al., 2013). Therefore, the main challenges for seismic sensor installation at this scale are (1) to locate the sensor at close distance to the sources, (2) to maximize the number of stations and to locate the sensor close to each other to record the same event at different seismic station, and (3) minimize the azimuthal gap between the sensors. The number of deployed sensors plays an important role in the magnitude of completeness $\left(M_{\mathrm{c}}\right)$ of the seismic network, while the geometry of the network (i.e., inter-sensor distances, azimuthal gap) mostly controls the accuracy of source locations.

Seismic sensors can be deployed in a network of single sensors or a network of sensor arrays. The difference between seismic networks and seismic arrays is related to the distance at which the signals recorded by two sensors can be correlated. In the case of seismic arrays, the distance between the sensors is reduced to maximize the correlation of the signals recorded by each sensor. Otherwise the installation is called a seismic network (Podolskiy and Walter, 2016). Although the inter-sensor distance is often small $(<1 \mathrm{~km})$ in the case of landslide monitoring, decorrelation of the signals is often observed even at small distances due to the complexity of the underground structure especially at high frequencies. The use of the seismic array approach in landslide monitoring often refers to specific geometries of collocated sensors (inter-sensors distances $<50 \mathrm{~m}$ ) organized with a central sensor (often a three-component seismometer) and several satellite sensors (often vertical sensors). This kind of installation presents many advantages such as enhancing the signalto-noise ratio and allowing the computation of the back azimuth of the source with beam-forming methods.

For the majority of the instrumented landslides, seismic networks are organized with single sensors located on or at close distance to the unstable slopes. The inter-sensors distance and the azimuthal gap are often controlled by the location of easily accessible or stable portions of the slopes. However, a specific geometry can be adopted such as (almost) a linear geometry. This is particularly the case for monitoring the propagation of debris flows in stream channels. Dense networks (number of sensors $>50$ ) can also be deployed. In this case, the sensors are installed using a grid geometry with regular inter-sensor distances. This kind of installation is probably the most optimal but is currently mostly realized during short acquisition campaigns due to the difficulty to maintain a large number of sensors over long periods (battery, data storage, possible movement of the sensor), especially when installed directly on the unstable zones of landslides. Finally, the installation of sensors at depth $(>1 \mathrm{~m})$ is challenging for landslides and it has currently only been realized on hard-rock slopes (e.g., Randa; Spillmann et al., 2007, or Séchilienne; RESIF/OMIV, 2015). This kind of in- 
stallation is, however, very valuable to constrain the depth of the sources.

\subsection{MS processing chains}

One of the current challenges for landslide MS analysis is the development of dedicated processing chains able to analyze the unconventional seismic signals observed on landslides. The three steps of MS processing are, successively, the detection, the classification and the location of the endogenous seismic events. The development of robust and versatile processing chains for analyzing landslide MS is challenging because of (1) the low magnitude of the events and the attenuation of the media that results in emergent and low signal-tonoise ratio records, (2) the seismic source radiation patterns that may be single centroid source, double couple source or volumetric source, and, (3) the heterogeneity and variation in time (i.e., topography, water table levels, fissures) of the underground structure preventing the construction of precise velocity models and hence, accurate source locations.

First, for detecting automatically or manually the seismic events, the use of spectrograms is common. Spectrograms represent the evolution of the frequency content in time by computing the Fourier transform on small moving time windows (e.g., < $1 \mathrm{~s}$ ). Automatic detection is usually carried out with the STA/LTA (short-term average/long-term average) detector (Allen, 1982) applied on the summed energy of the spectrogram (Spillmann et al., 2007; Helmstetter and Garambois, 2010; Tonnellier et al., 2013).

Second, classifying the detected signals can be carried out automatically by discarding exogenous events with simple criteria (i.e., threshold on the signal duration, inter-trace correlation, apparent velocity) but the determination of the threshold to differentiate the class of signals may be difficult. Machine learning algorithms offer nowadays the possibility to automatize and improve this step. Dammeier et al. (2016) developed a hidden Markov model (HMM) that can detect automatically in the time series the occurrence of one particular type of events. The success rate of HMM is reasonable and this technique has the advantage of requiring only one single example to scan the time series. The Random Forest algorithm has proven its efficiency for volcanic and landslide signals classification with higher success rate and versatility (Provost et al., 2017a; Hibert et al., 2017c). New signals are successfully classified into multiple pre-defined classes and changes in the source properties may be detected by change on the uncertainties (Hibert et al., 2017c). It must be noticed that this approach requires a training set with sufficient elements to build the model. Good success rates (i.e., $>85 \%$ ) are rapidly reached with 100 elements or more per class. Template-matching filters have also been used in many studies of landslide collapse and glaciers (Allstadt and Malone, 2014; Yamada et al., 2016a; Poli, 2017; Helmstetter et al., 2015a, b; Bièvre et al., 2017; Helmstetter et al., 2017a) in order to detect and classify seismic signals. This method con- sists of scanning continuous data to search for signals with waveforms similar to template signals. It can detect seismic signals of very small amplitude, smaller than the noise level. Seismic signals are grouped in clusters of similar waveforms, implying similar source locations and focal mechanism.

Finally, the location of the sources is the most challenging step. Common location methods (such as NonLinLoc; Lomax et al., 2000, 2009) were used in combination with 3$\mathrm{D}$ velocity models for locating impulsive microearthquakes occurring at the Randa rockslide (Spillmann et al., 2007). However, a certain number of recorded signals do not exhibit impulsive first arrivals and clear P- and S-wave onsets. For this kind of signal, location methods based on the inter-trace correlation of the surface waveform (Lacroix and Helmstetter, 2011) or on the amplitude (Burtin et al., 2016; Walter et al., 2017) are more suitable and easier to automatize. Other methods such as HypoLine (Joswig, 2008) aim at integrating different strategies (i.e., first arrival picking, inter-trace correlation and beam-forming) to accurately locate the epicenter under the control of an operator, while (Provost et al., 2018) developed a method combining amplitude source location and inter-trace correlation of the first arrivals in an automatic scheme. In most of the studies, the media attenuation field and/or the ground velocity are approximated to a 1-D model, and/or do not take into account the topography. Both the complexity of the landslide underground structure and of the recorded seismic signals lead to mislocation of the events that prevents the accurate interpretation of certain sources and leads to false alarms (Walter et al., 2017).

\subsection{Instrumented sites}

In the last two decades, seismic networks have been installed on several unstable slopes worldwide. Table 1 summarizes the unstable slopes or debris-flow-prone catchments instrumented with seismic sensors worldwide. The sites are classified in terms of landslide types (i.e., slide, fall or flow) according to the geomorphological typology of (Cruden and Varnes, 1996). Studies on snow avalanches (Lawrence and Williams, 1976; Kishimura and Izumi, 1997; Sabot et al., 1998; Suriñach et al., 2001; Biescas et al., 2003) are not integrated. Most of the instrumented sites are located in the European Alps (France, Italy and Switzerland). Short-period (SP) seismometers and Geophones (G) are the most common type of instruments. Their installation and maintenance is easy as they do not require mass calibration in comparison to broadband (BB) or long-period (LP) seismometers.

\section{Data}

Seismic observations from 13 sites are used to propose the typology. The sites are representative of various types of slope movements and lithology (Table 1) with four slides occurring in hard rocks, four slides occurring in soft rocks, three rockfall-prone cliffs occurring in hard and soft rocks, and one 
catchment prone to debris flows. The seismic instruments installed on these sites are recording the seismicity generated by the slope deformation and are installed either permanently or were acquired during short campaigns (Table 1). The Riou Bourdoux catchment is the only site where the seismic signals were manually triggered as rock blocks were thrown down the cliff and monitored with cameras, lidar and seismic sensors (Hibert et al., 2017a).

The dimensions of the unstable slopes range from $60 \mathrm{~m} \times 30 \mathrm{~m}$ for the Chamousset cliff to $7 \mathrm{~m} \times 300 \mathrm{~m}$ for the Saint-Eynard cliff (Table 2). The seismic networks are deployed with various geometry depending on the configuration of the slope, its activity and the duration of the installation. For most of the sites, at least one seismic sensor is deployed on the active zone or very close to it (Table 2). The maximal distance to the slope instabilities is $500 \mathrm{~m}$ for the Saint-Eynard cliff being the largest investigated site of our study.

The seismic network geometry of the majority of sites is a distributed seismic network where sensor locations are regularly installed over the active zone or in its vicinity. In the case of the Rebaixader catchment, the seismic network is installed at the border of the stream channel almost linearly. At the Slumgullion landslide, a dense network has been installed with regular spacing of the seismic sensors. Seismic arrays are installed at the other sites. The geometry of the seismic arrays are triangular in shape with the exception of the Séchilienne landslide where an hexagonal shape is used.

The instruments are mostly SP seismometers with natural frequencies of 1 to $5 \mathrm{~Hz}$. Fewer geophones and BB seismometers are installed at the sites. The instrument response is corrected for all of the dataset. To be consistent with the sensitivity of all the sensors, we do not investigate the data below $1 \mathrm{~Hz}$ for BB seismometers or above $100 \mathrm{~Hz}$ for SP seismometers and geophones.

The dataset being analyzed is composed of either published seismic events or published catalogs. The comparison of these events and catalogs enable us to compare the signals and to compose the classes of the typology. In the case that no published events or catalogs are available, we manually analyzed the dataset to complete the number of examples for each proposed class (see Sect. 5 for detailed information).

\section{Methodology}

The seismic signals recorded at different sites are compared in order to identify common features. Seismic signals result from the convolution of both the wave propagation and of the seismic source mechanism. Consequently, the observation of common signal features in signals recorded at different sites can only be explained by similar source mechanisms. The proposed typology is hence based on the analysis of these common features. We then selected nine signal features in order to quantify the differences and similarities between the different classes. The nine parameters are chosen because they correspond to the criteria used by experts to analyze and classify a seismic signal and also because they can be used in automatic classification algorithms (Fäh and Koch, 2002; Langer et al., 2006; Curilem et al., 2009; Hammer et al., 2012, 2013; Hibert et al., 2014a; Ruano et al., 2014; Maggi et al., 2017; Provost et al., 2017a; Hibert et al., 2017c). They can be computed for any signal type and present a robust framework for future comparison. The selected signal features are the following.

- The duration of the signal $T$ (expressed in seconds) is computed on the stacked spectrogram of the traces (Helmstetter and Garambois, 2010).

- The dissymmetry coefficient of the signal (expressed in percent) is computed as

$s=\frac{t_{m}-t_{1}}{t_{2}-t_{1}} \times 100$,

where $t_{1}, t_{2}$ and $t_{m}$ are the time of the signal onset, ending and maximum, respectively.

- The number of peaks of the signal envelop $N_{\text {peaks }}$, computed as the number of local maximum above $50 \%$ of maximal value of the signal envelop. The envelop of the signal is computed as the absolute value of the Hilbert transform of the signal. The envelop is smoothed by computing the average on a moving window of length $\delta t=\frac{100}{f_{s} T}$.

- The duration of the signal autocorrelation is defined as

$T_{\text {corr }}=\frac{t_{c}}{T}$,

with

$t_{c}=\max _{t}(C(t)<0.2 \times \max (C))$,

where $C$ is equal to the signal autocorrelation. $T_{\text {corr }}$ is expressed in percent (\%) and represents the duration of the signal correlating with itself. As an example, a signal with a rapid and abrupt change in frequency content will rapidly be uncorrelated (low $T_{\text {corr }}$ ), while a signal with a constant frequency content will have a long autocorrelation (high $T_{\text {corr }}$ ).

- The mean frequency (expressed in hertz) is computed as

$F_{\text {mean }}=\frac{\sum_{i=1}^{N} \operatorname{PSD}\left(f_{i}\right) f_{i}}{\sum_{i=1}^{N} \operatorname{PSD}\left(f_{i}\right)}$

with the power spectral density (PSD) defined as

$\operatorname{PSD}(f)=\frac{2|\mathrm{FFT}(y)|^{2}}{N f_{s}}$, 
Table 2. Characteristic of the seismic network for the 13 sites analyzed in the present parer. The landslide dimensions are given for the most active area of the slope instabilities (as presented in the published studies). The total number of sensors in the seismic network are given, as well as the minimal and maximal inter-sensor distance and distance to the active zone. In the cases where only a few of the sensors have been investigated in the present study, we indicate the number of the sensors as well as the name of the station in parenthesis.

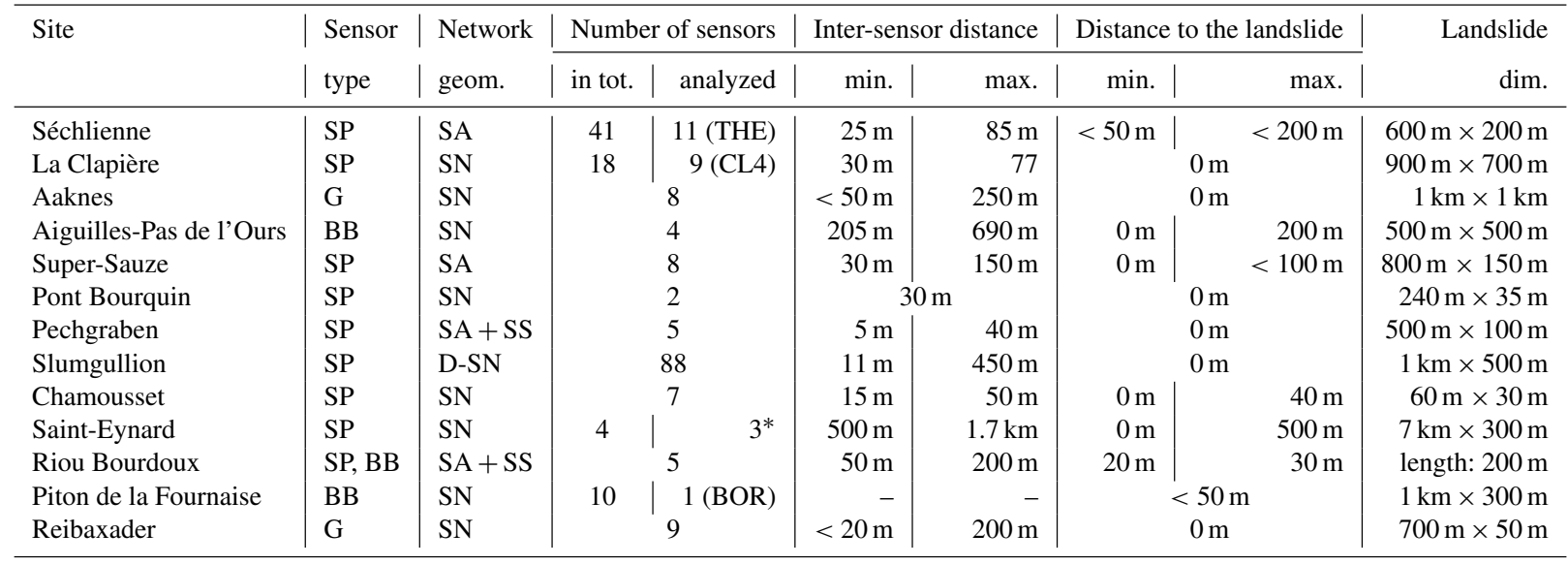

G: geophone $(f=[0.1-10] \mathrm{kHz})$; SP: short-period $(f=[0.1-100] \mathrm{Hz})$; BB: broadband $\left(f=\left[10^{-2}-100\right] \mathrm{Hz}\right)$; SN: seismic network; D-SN: dense-seismic network; SA: seismic array; L-SA: linear-seismic array; SS: single sensor; ${ }^{*}$ investigated stations: FOR, MOL and GAR.

where $f_{s}$ and $N$ are the sampling frequency of the signal and the number of samples, respectively. The mean frequency is chosen here as it is more representative of the signal spectrum energy and less sensitive to noise than the frequency of maximum energy. (Farin et al., 2014).

- The frequency corresponding to the maximal energy of the spectrum is denoted $F_{\max }$ (expressed in hertz).

- The frequency bandwidth $F_{w}$ is defined as

$$
F_{w}=2 \sqrt{\frac{\sum_{i=1}^{N} \operatorname{PSD}\left(f_{i}\right) f_{i}^{2}}{\sum_{i=1}^{N} \operatorname{PSD}\left(f_{i}\right)}-F_{\text {mean }}^{2}} .
$$

- The minimal frequency of the signal spectrum is computed as

$$
f_{\min }=\min _{f}(\operatorname{PSD}(f)<0.2 \times \max (\mathrm{PSD})) .
$$

- The maximal frequency of the signal spectrum is computed as

$$
f_{\max }=\max _{f}(\operatorname{PSD}(f)<0.2 \times \max (\mathrm{PSD})),
$$

which is the maximal frequency of the signal spectrum $f_{\max }$ (not to be confused with parameter $F_{\max }$ defined above).

The signal features are always computed on the trace with the maximal amplitude passed in the band $\left[f_{c}-50\right] \mathrm{Hz}\left(f_{c}\right.$ : natural frequency). This enables is to limit the influence of the wave propagation and to compare signals with different sampling frequencies (i.e., 120 to $1000 \mathrm{~Hz}$ ).
Based on already published events and further interpretations, we propose a standard classification of landslide endogenous seismic sources. The unpublished datasets are used to investigate the presence of these signals at other sites and to increase the number of examples for different contexts. Numerous signals were analyzed to draw the proposed classification and selected examples are further presented to describe the different classes.

\section{Seismic description of the signals - typology}

The typology of the signals is based on the duration and the frequency content of the seismic signals. The signals are classified into three main classes: "slopequake" (SQ), "rockfall" (RF) and "granular flow" (GF). For slopequake, subclasses are proposed and discussed based on the frequency content of the signals. Several examples of signals recorded at different sites are presented and the sources are discussed in the corresponding section.

\subsection{Rockfall (RF)}

Figure 2 displays the seismic waves recorded for a single block fall at the Riou Bourdoux catchment (French Alps). The block was manually launched in the catchment and recorded with seismic sensors and cameras (Hibert et al., 2017a). The signal is characterized by successive impacts visible both on the waveform and on the spectrograms and lasts around $20 \mathrm{~s}$. The spectral content contains mostly frequencies above $10 \mathrm{~Hz}$ but energy below $10 \mathrm{~Hz}$ is present for certain impacts (Fig. 2a). At closer distance, very high frequencies can be recorded up to $100 \mathrm{~Hz}$ (Fig. 2a). The autocorrelation remains large over time due to the simili- 


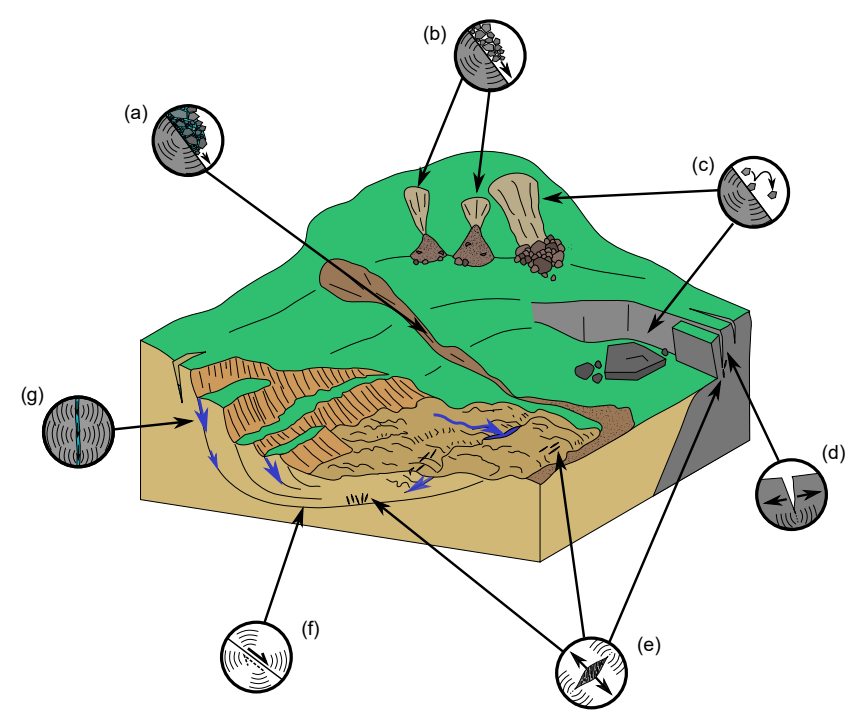

Figure 1. Conceptual scheme of the landslide endogenous seismic sources with (a) wet granular flow, (b) dry granular flow, (c) rockfall, (d) tensile fracture opening, (e) tensile cracks opening, (f) shearing and (g) fluid migration in fracture.

tude of the individual impact signals $\left(T_{\text {corr }}>10 \%\right)$. $\mathrm{P}$ and $\mathrm{S}$ waves are hardly distinguishable on the record and the signals recorded at the seismic sensors are dominated by surface waves (Dammeier et al., 2011; Helmstetter and Garambois, 2010; Hibert et al., 2014a; Levy et al., 2015).

Seismic signals of natural masses detaching from cliffs are presented in Fig. 3. They present similar characteristics to the artificially triggered rockfall. Depending on the height of the cliff, the signal ranges from 5 seconds up to tens of seconds. The symmetry of the signal ranges from 0 to $80 \%$ depending on the cliff configuration. In general, the most energetic impacts are recorded at the middle or after the middle of the signal (dissymmetry coefficient $>50 \%$ ). The highest measurable frequency depends on the source-to-sensor distance and can be very high $(>100 \mathrm{~Hz})$. The spectral energy is concentrated in frequencies above $5 \mathrm{~Hz}$, with the largest PSD values $\left(F_{\max }\right)$ ranging from 20 to $40 \mathrm{~Hz}$. Generally, the PSD energy is low below $10-15 \mathrm{~Hz}$ with the exception of one case (Fig. 5c) where spectral energy can be observed. The initial falling masses can themselves break into smaller units during propagation. In this case, the signal does not return to the noise level between the impacts due to developing granular flow (Fig. 3b, e, f) leading to a decrease in the duration of the autocorrelation of the signal. When several blocks are falling at the same time, impacts may overlap, and so do the peaks of the signals. In certain cases, the first rock free fall is preceded by a signal that can be associated with the rock detachment. An example of this precursory signal can be observed in Fig. 3a, f and in the data reported by Hibert et al. (2011) and Dietze et al. (2017b). The seismic signals of rockfalls contain information on the physics of the pro- cess. The seismic energy of rockfall signals is proportional to the volume (Hibert et al., 2014a; Farin et al., 2014). Scaling laws have also been established between seismic energy, momentum, block mass and velocity before impacts (Hibert et al., 2017a). The frequency content is mainly controlled by the block mass. The frequency of the spectral maximum energy decreases when the block mass increases (Farin et al., 2014; Huang et al., 2007; Burtin et al., 2016). If the rockfalls are well isolated, each impact generates impulsive waves. In the case of multiple rockfalls or short distances between the seismic sources and the sensors, the first arrivals may be emergent due to simultaneous arrivals of waves generated by impactors of different sizes impacting the ground at closely spaced time intervals (Levy et al., 2015; Hibert et al., 2014a).

\subsection{Granular flow (GF)}

Granular flows are characterized by cigar-shape signals lasting between tens to thousands of seconds. They are subdivided in two classes.

- Dry granular flow (Fig. 4): These signals are characterized by cigar-shape waveforms of long duration $(<$ $500 \mathrm{~s}$ ). Due to the absence of water, the source generally propagates over small distances. The duration of autocorrelation is very weak $\left(T_{\text {corr }} \approx 0 \%\right)$ and no seismic phase can be distinguished. No distinguishable impacts can be observed in the waveform nor in the spectrogram unlike rockfall signals. The signal onset is emergent, $\mathrm{P}$ and $\mathrm{S}$ waves are hardly distinguishable and the signal is dominated by surface waves (Deparis et al., 2008; Dammeier et al., 2011; Helmstetter and Garambois, 2010; Hibert et al., 2014a; Levy et al., 2015). The dissymmetry coefficient of the signal varies between $30 \%$ and $75 \%$ and depends on the acceleration and the volume of mass involved in the flow through time (Suriñach et al., 2001, 2005; Schneider et al., 2010; Levy et al., 2015; Hibert et al., 2017b). The frequency ranges from 1 to $35 \mathrm{~Hz}$. The maximal frequency of the PSD varies between 5 and $10 \mathrm{~Hz}$ and can be larger (up to $20 \mathrm{~Hz}$ ) when the seismic sensors are located close to the propagation path. The PSD values are significantly low below $3 \mathrm{~Hz}$ and increase rapidly between 3 and $20 \mathrm{~Hz}$.

- Wet granular flow (Fig. 5): These signals range from several thousands of seconds to several hours and correspond to debris flows. They occur during rainfall episodes when fine material and boulders propagate downstream over long distances $(>500 \mathrm{~m})$. Like dry granular flow, the duration autocorrelation is very weak $\left(T_{\text {corr }}=0 \%\right)$ and no seismic phase can be distinguished. The seismic sensors are often installed at very close distance to the flow path so high frequencies up to $100 \mathrm{~Hz}$ may be recorded (Abancó et al., 2014; Burtin et al., 2016; Walter et al., 2017). Little energy is present in the low frequencies $(<10 \mathrm{~Hz})$ depending on the amount of 
(a) Riou Bourdoux

09-Sep-2015 12:57:12
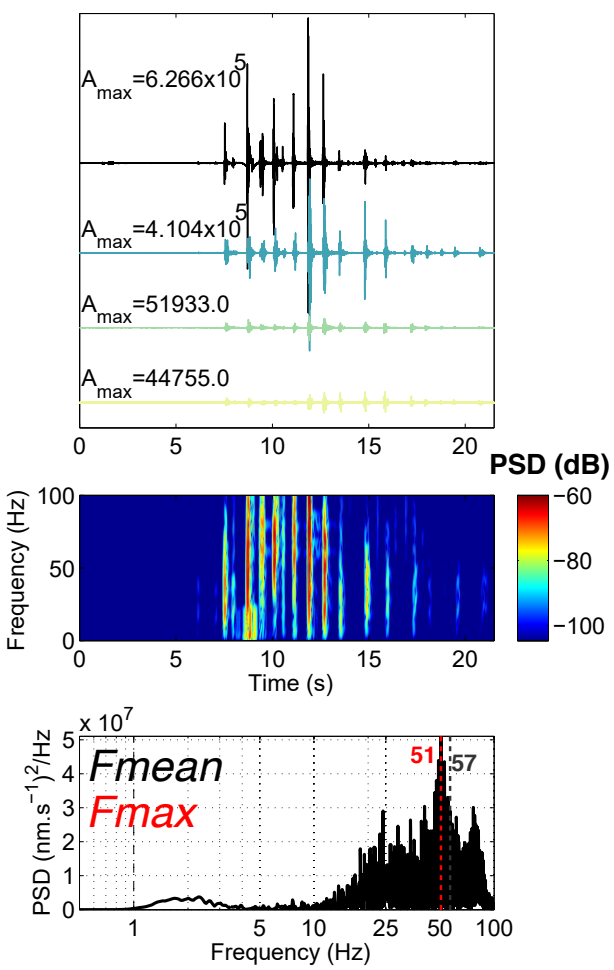

(b) Riou Bourdoux
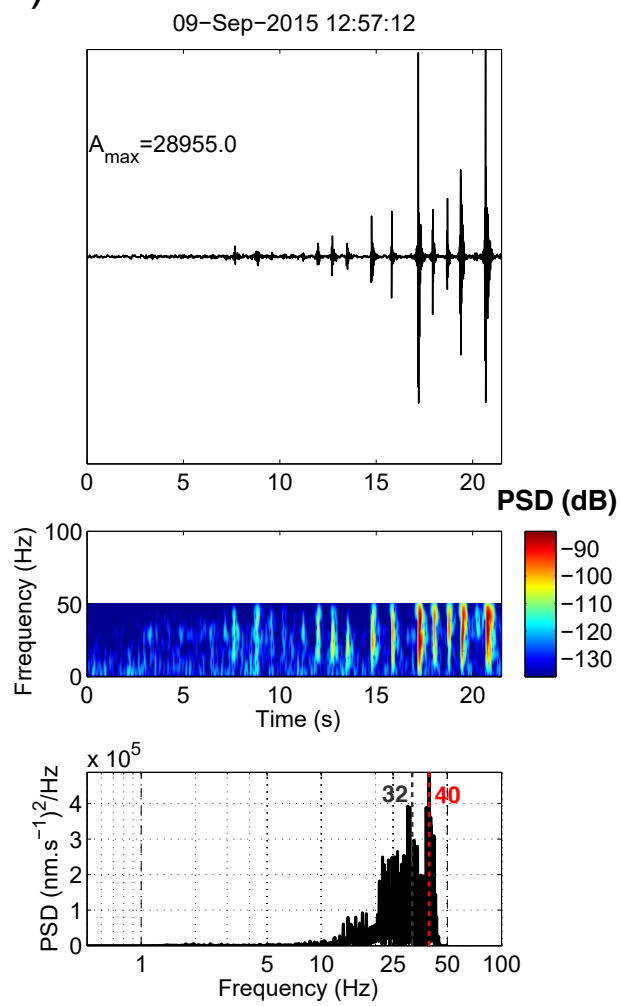

Figure 2. Example of one controlled rockfall (mass $=430 \mathrm{~kg}$ ) at the Riou Bourdoux catchment (Hibert et al., 2017a) recorded by a SP seismometer located at $50 \mathrm{~m}$ from the rock departure (a) and recorded by a BB seismometer near the rock arrival (b). The waveforms of the vertical traces are plotted in the upper part of the figure. The amplitude are normalized on the trace with the maximal amplitude (black), the signal recorded by the other sensors (when available) are represented in color below. The maximal amplitudes $\left(A_{\max }\right)$ of all the traces are plotted on the subplot in $\mathrm{nm} \mathrm{s}^{-1}$. The spectrogram is plotted on the middle part of the figure and normalized to the maximal energy. The lower part of the figure represents the PSD of the most energetic trace and the frequency corresponding to the maximum and the mean of the PSD are plotted in red and gray, respectively.

water and the size of the rocky blocks integrated in the flow (Burtin et al., 2016). The signal is emergent and the amplitude variation depends on the mass involved in the flow passing in the vicinity of the sensor. Debris flows are very often divided into a front with the largest boulders and the highest velocity followed by a body and a tail where the sediment concentration and the velocity decrease (Pierson, 1995). The seismic signal amplitude hence increases progressively as the front is passing in the vicinity of the sensor (Abancó et al., 2012; Hürlimann et al., 2014; Burtin et al., 2016; Walter et al., 2017), and decreases progressively as the front is moving away from the sensor (dissymmetry coefficient $>50 \%$ ). Large spikes and low frequencies may be observed in the seismic signal corresponding to the front of the debris flow generated by large boulder impacts. The frequency content also changes and, progressively, energy in the lower frequencies decreases (Fig. 5a).

\subsection{Slopequake (SQ)}

The "slopequake" class gathers all the seismic signals generated by sources located within the slope at the subsurface or at depth such as fracture-related sources or fluid migration (cf. Sect. 2). Different names have already been proposed for this kind of signals: "slidequakes" (Gomberg et al., 2011), "micro-earthquake" (Helmstetter and Garambois, 2010; Lacroix and Helmstetter, 2011), "quakes" (Tonnellier et al., 2013; Vouillamoz et al., 2018) or "landslide micro-quake (LMQ)" (Brückl, 2017). We here proposed the term "slopequake" as a general name for these events. They are characterized by short duration $(<10 \mathrm{~s})$ and are subdivided into two classes "simple" and "complex". 
(a) Super-Sauze
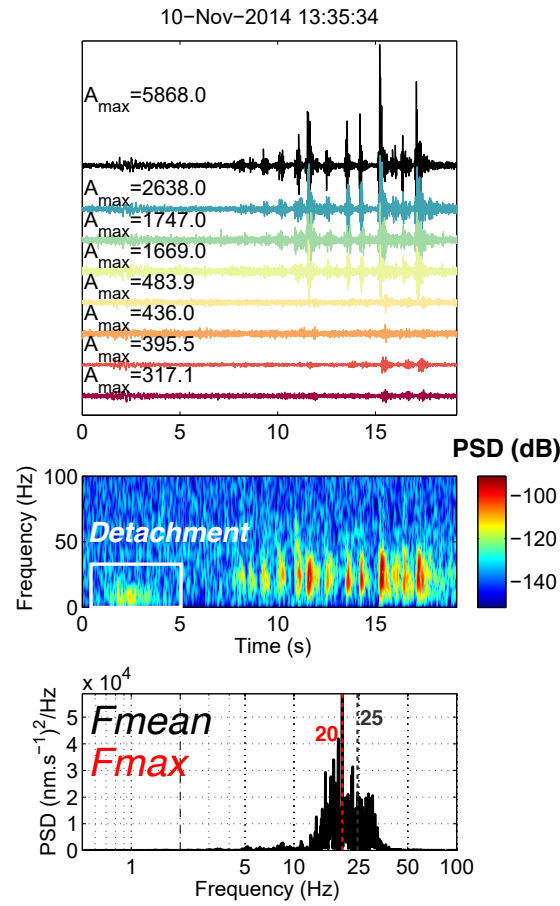

(d) Super-Sauze
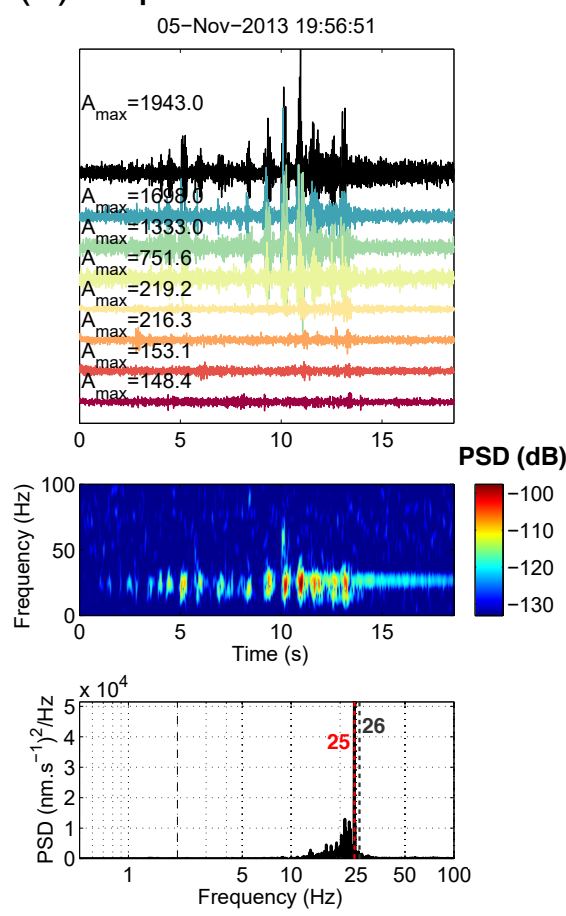

(b) Séchilienne
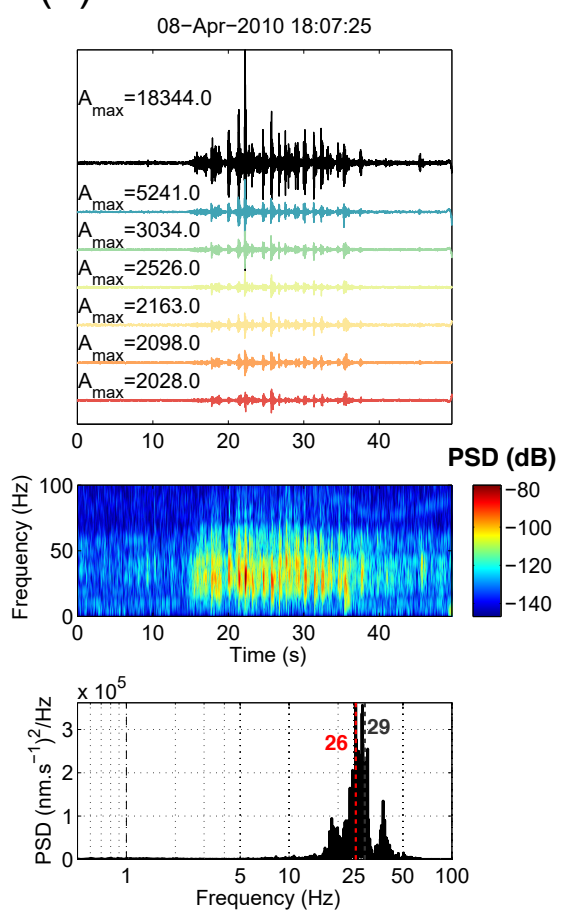

(e) Aaknes
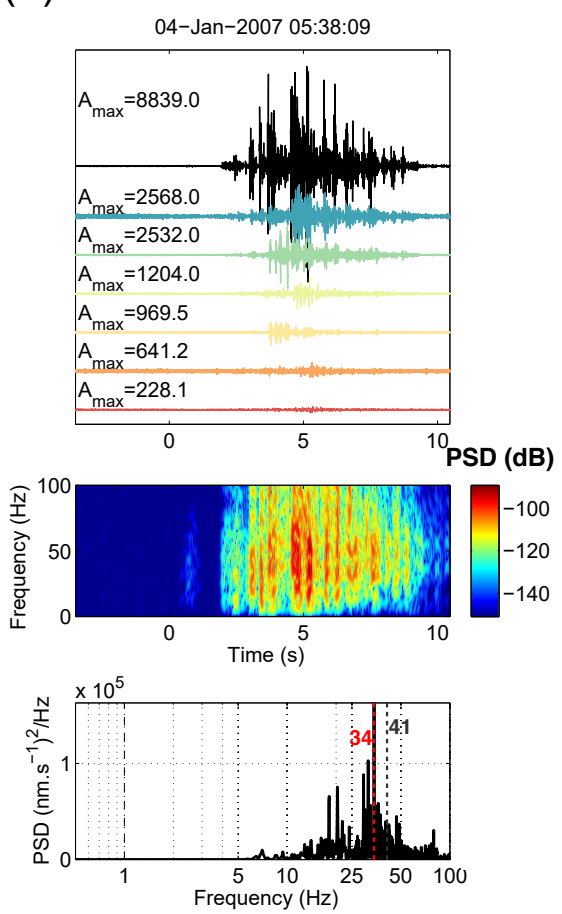

(c) Chamousset
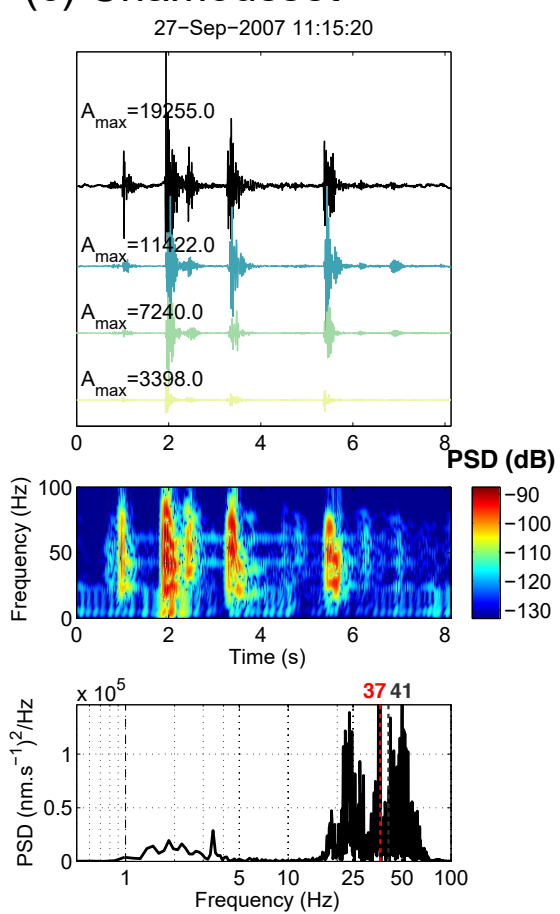

(f) Mount St-Eynard
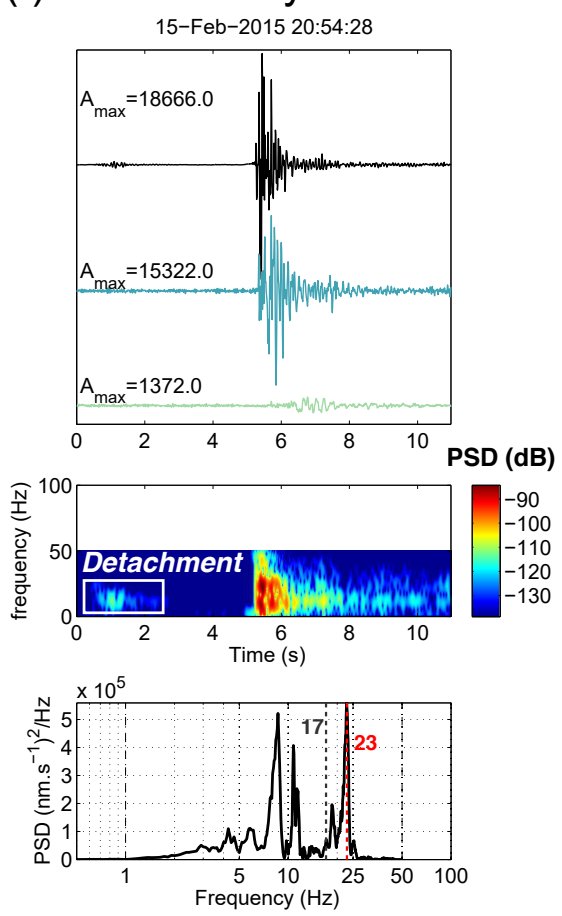

Figure 3. Rockfall events recorded at (a) and (d) Super-Sauze (France; Provost et al., 2017a), (b) at the Séchilienne (France; Helmstetter et al., 2011; RESIF/OMIV, 2015), (c) Chamousset (Levy et al., 2011), (e) Aaknes and (f) Mount Saint-Eynard slopes (Le Roy et al., 2018). See Fig. 2 for a description of the figure. 
(a) Séchilienne
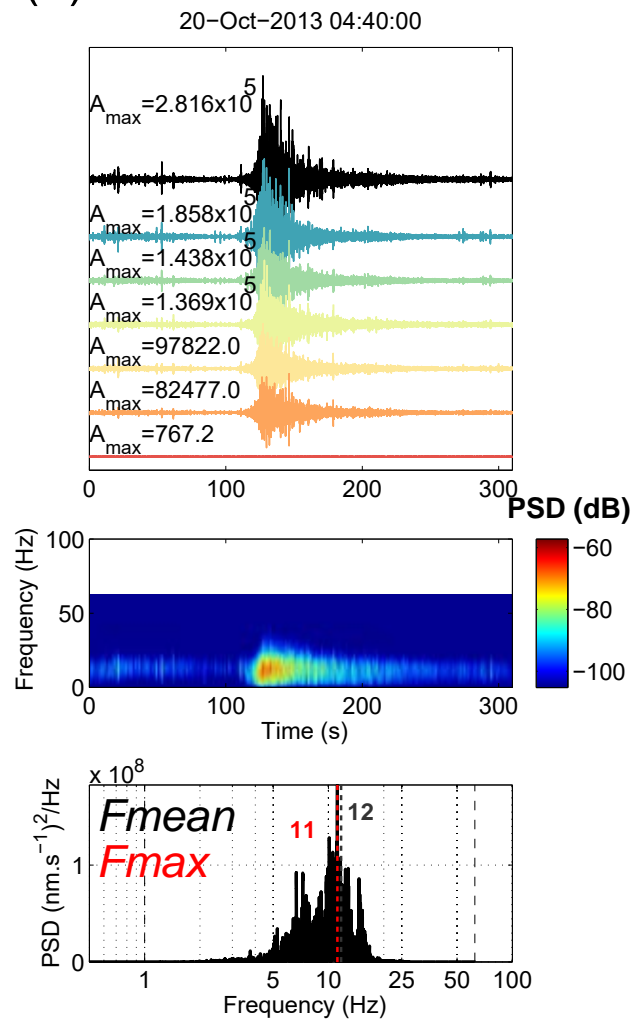

(b) Piton de la Fournaise

03-Nov-2009 22:25:41
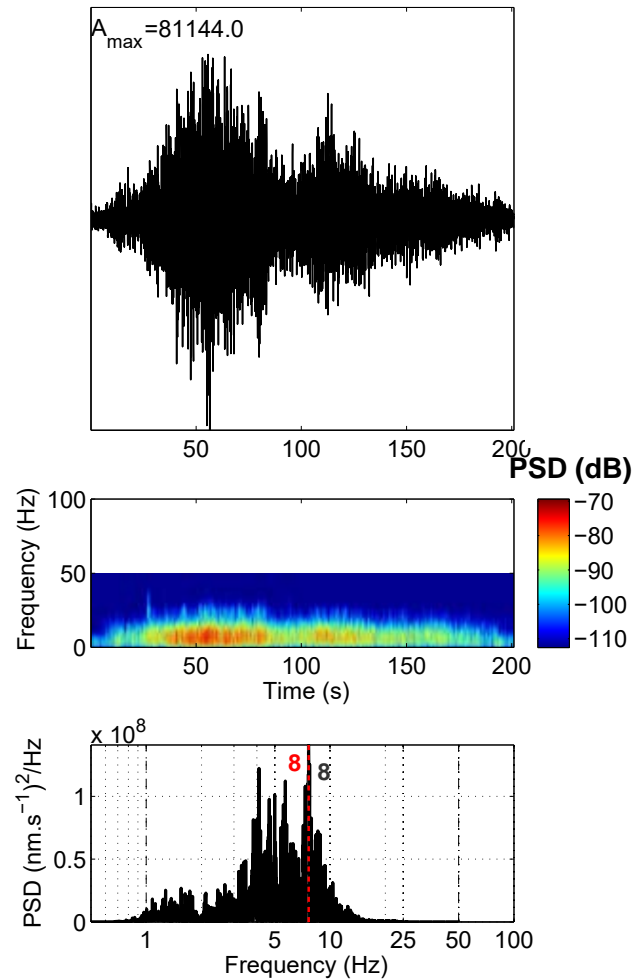

Figure 4. Dry granular flow events recorded at (a) Séchilienne and (b) the Piton de la Fournaise caldera. See Fig. 2 for a description of the figure.

\subsubsection{Simple slopequake}

"Simple slopequake" signals are of short $(<2 s)$ to very short duration $(<1 \mathrm{~s})$. Their main feature is the triangular-shape of the spectrogram with largest amplitudes being recorded in the first part of the signal (dissymmetry coefficient $<50 \%$ ). The first arrivals contain the highest frequencies of the signal and are followed by a decrease in the frequencies. Depending on the frequency content, these signals can be subdivided into three classes.

- Low-frequency slopequake (LF-SQ) (Fig. 6): The signal lasts between 1 and $5 \mathrm{~s}$. The maximal amplitude of the signal waveform occurs at the beginning or at the center of the signal $(15 \%<$ dissymmetry coefficient $<50 \%)$. The waveform presents only one peak and most of the first arrivals are emergent. Phase onsets are difficult to identify. The signals are mostly dominated by surface waves. Consequently, the duration autocorrelation of the signals is large (>10\%). The largest PSD values are observed between 5 and $25 \mathrm{~Hz}$ with a mean frequency ranging between 10 and $15 \mathrm{~Hz}$.

- High-frequency slopequake (HF-SQ) (Fig. 7): The signal lasts between 1 and $5 \mathrm{~s}$. The maximal amplitude of the signal waveform occurs close to the beginning of the signal (dissymmetry coefficient $<30 \%$ ). The waveform presents only one peak and the first arrivals are mainly impulsive. Different phases may be observed (Spillmann et al., 2007; Lévy et al., 2010): P arrivals are detected at the beginning of the signal and correspond to the high-frequency waves, surface waves are then observed at the time the frequency decreases. However, in general the short sensor-to-source distance makes the differentiation between the different seismic phases difficult. The autocorrelation of these signals is hence lower than for LF-SQ $(<10 \%)$. In most of the cases, the picking of the different wave onsets is made difficult because of the sensor-to-source distances and the low-frequency sampling. The largest PSD values are observed between 3 and $45 \mathrm{~Hz}$ with a mean frequency ranging between 20 and $30 \mathrm{~Hz}$.

- Hybrid slopequake (Hybrid-SQ) (Fig. 8): The signal lasts between 1 and $2 \mathrm{~s}$. It presents the characteristics of the two precedent signals. The brief first arrivals are very impulsive and last less than 1 second. They are followed by a low-frequency coda similar to the LF-SQ. The maximal amplitude of the signal waveform occurs 
(a) Rebaixader

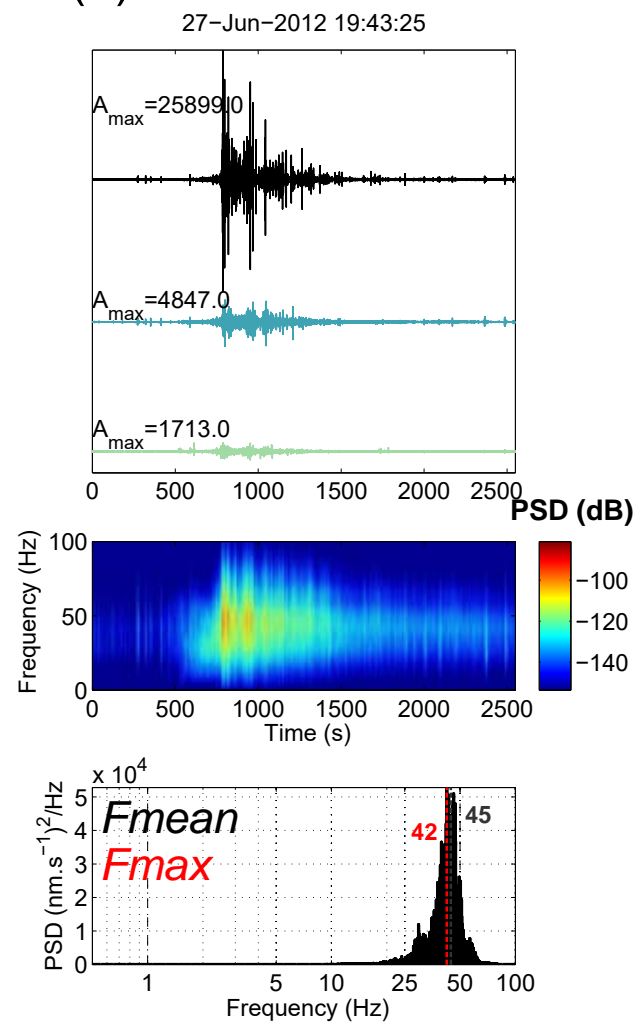

(b) Rebaixader

04-Jul-2012 20:13:11
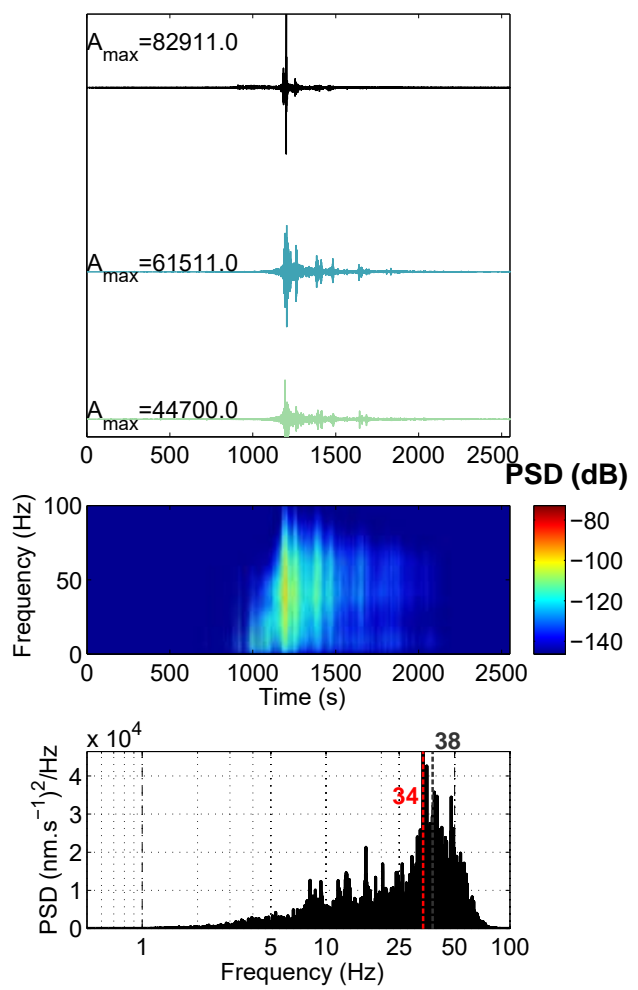

Figure 5. Wet granular flow events recorded at Rebaixader torrent (Abancó et al., 2012; Hürlimann et al., 2014; Arattano et al., 2016). See Fig. 2 for a description of the figure.

close to the beginning of the signal (dissymmetry coefficient $<40 \%$ ). The waveform presents only one peak and the first arrivals are impulsive.

These signals are suspected to be associated with boundary or basal sliding (Helmstetter and Garambois, 2010; Gomberg et al., 2011; Walter et al., 2013b; Tonnellier et al., 2013) or fracturing of the slope (Helmstetter and Garambois, 2010; Colombero et al., 2018). Currently, only few studies have proposed inversion of the source tensor (Lévy et al., 2010). To the best of our knowledge, for soft-rock landslides, no source mechanism was modeled. Therefore, it remains difficult to see if the observation of LF- and HF-SQs is due to attenuation of the high frequencies with the distance or to the source mechanism. Indeed, the rupture velocity may explain the difference in frequency content and low-frequency earthquakes are observed on tectonic faults (Shelly et al., 2006; Brown et al., 2009; Thomas et al., 2016). They are characterized by low magnitude $\left(M_{w}<2\right)$ and short duration $(<1 \mathrm{~s})$ and constitute at least part of the seismic tremor signal. Therefore, the main assumption for the source of these events is slow rupture (Thomas et al., 2016). Another interpretation for the low-frequency quakes dominated by surface waves is crevasse opening (at the surface) as observed in glaciers (Deichmann et al., 2000; Mikesell et al., 2012). Colombero et al.
(2018) analyzed AE at laboratory scales generated during thermal fracturing. During this experiment, high-frequency AEs are recorded during the heating stage up to the failure of the rock sample and are interpreted as thermal cracking events (Colombero et al., 2018). Low-frequency AEs are recorded during the cooling stage (after failure) and are associated with stick-slip events (Colombero et al., 2018).

Hybrid slopequakes are very similar to the events recorded on volcanoes and glaciers with the presence of fluids in conduits or crevasses (Chouet, 1988; Helmstetter et al., 2015b). The sources of these events are assumed to be related to hydro-fracturing. The first high-frequency events corresponding to a brittle failure is followed by water flow into the newly opened cracks (Chouet, 1988; Benson et al., 2008).

The frequency content depends on the sensor-to-source distance and on the source mechanism. Observation of LFand HF-SQ may be the signature of ongoing processes taking place within the slope instabilities justifying the three proposed classes for simple slopequakes.

\subsubsection{Complex slopequake}

The second class of short-duration signals has the same general properties as the simple slopequakes but exhibits par- 
(a) Slumgullion
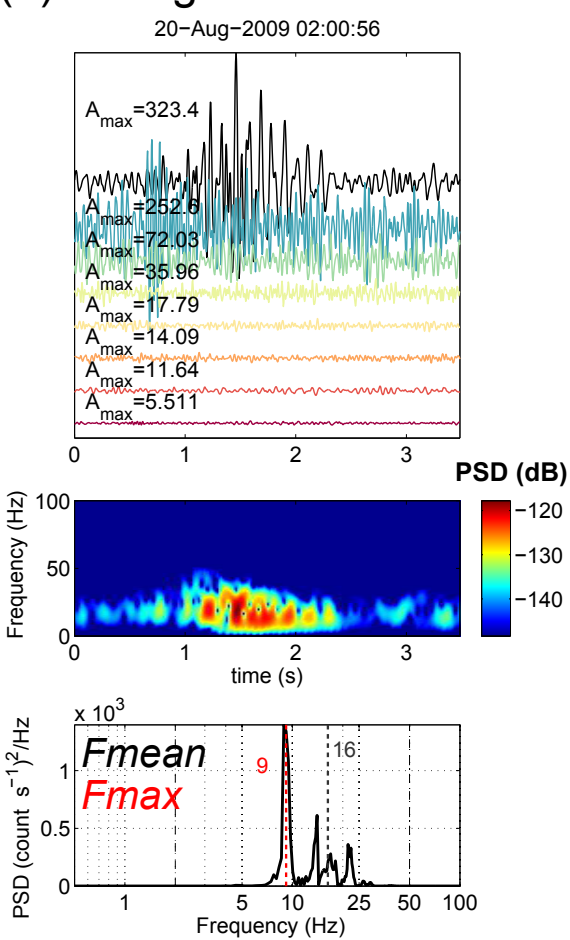

(c) La Clapière
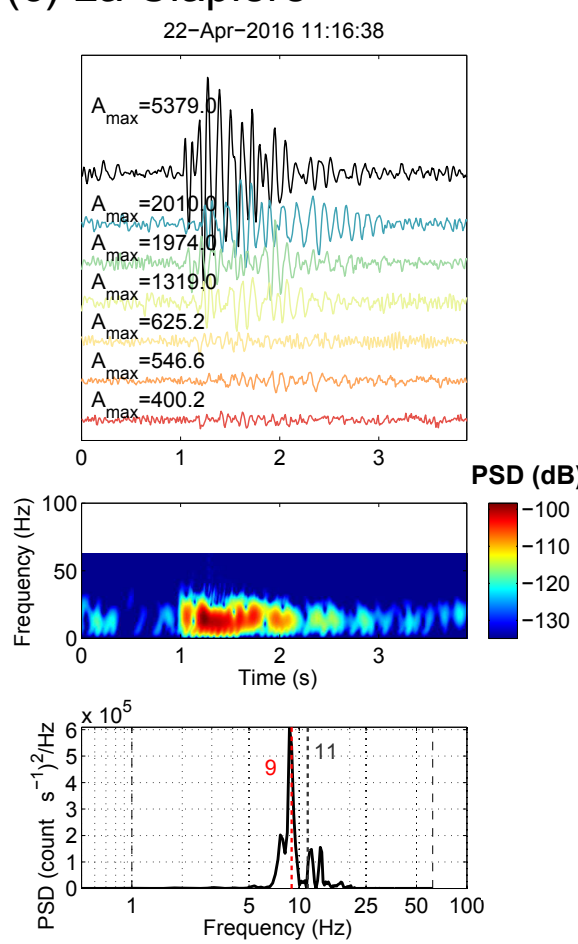

(b) Pont Bourquin
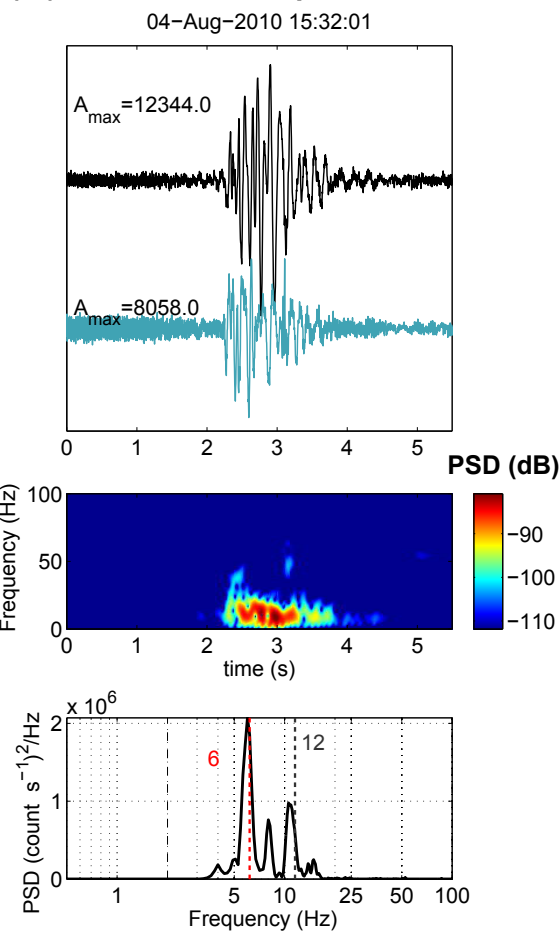

(d) Aiguilles-Pas de l'Ours
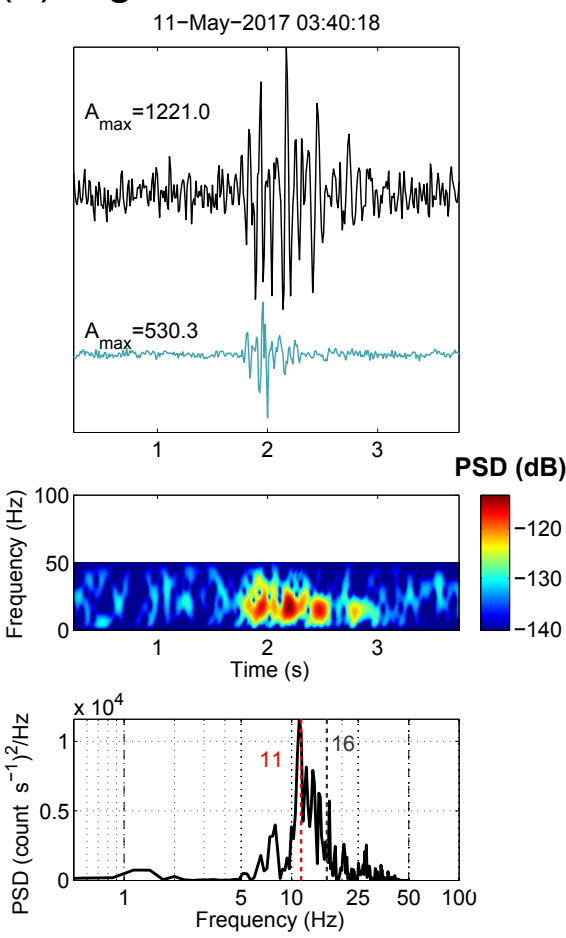

Figure 6. Low-frequency slopequakes recorded at the (a) Slumgullion (Gomberg et al., 2011), (b) Pont Bourquin, (c) La Clapière and (d) Aiguilles-Pas de l'Ours slopes. See Fig. 2 for a description of the figure. Note that for the Slumgullion signals (a), the amplitudes are expressed in counts. 
(a) Super-Sauze
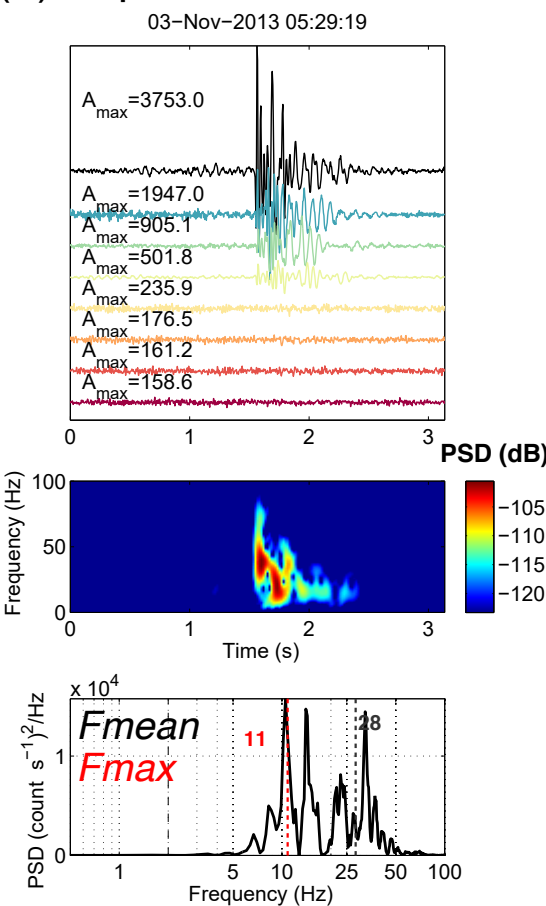

(d) La Clapière
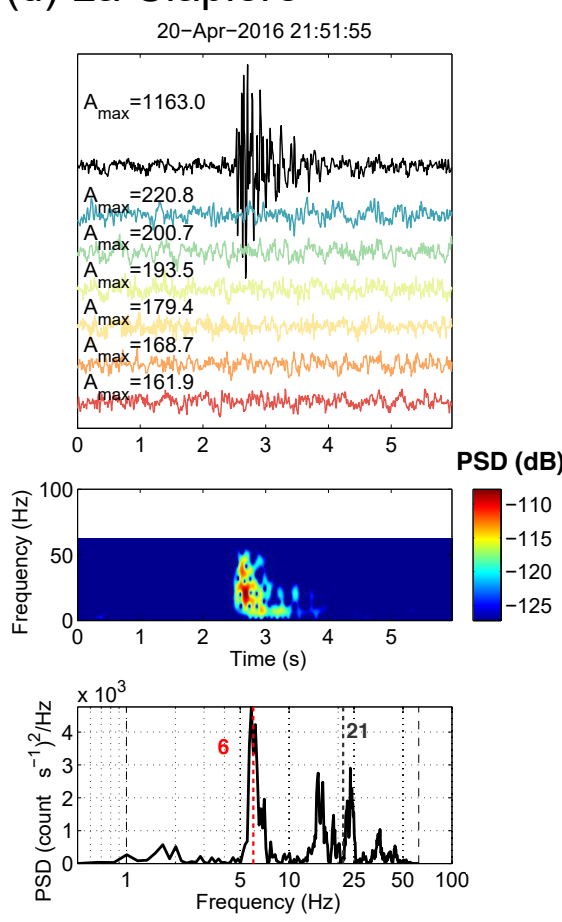

(b) Séchilienne
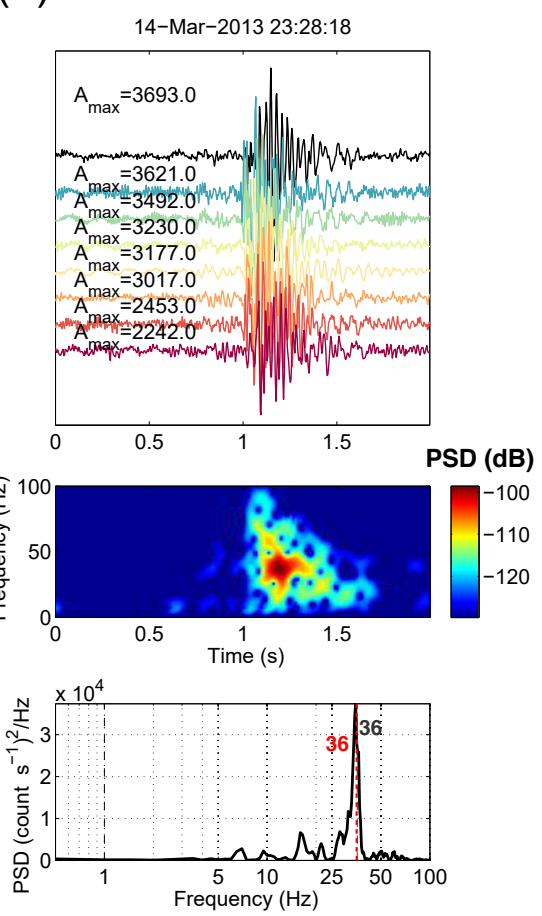

(e) Aaknes

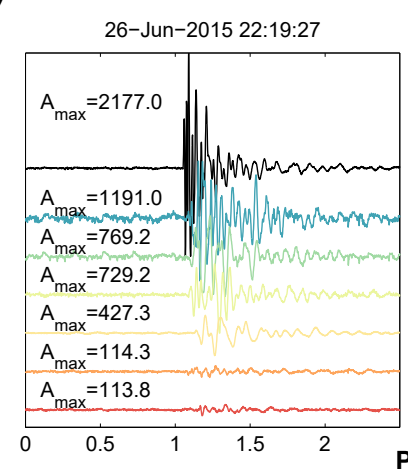

PSD (dB)
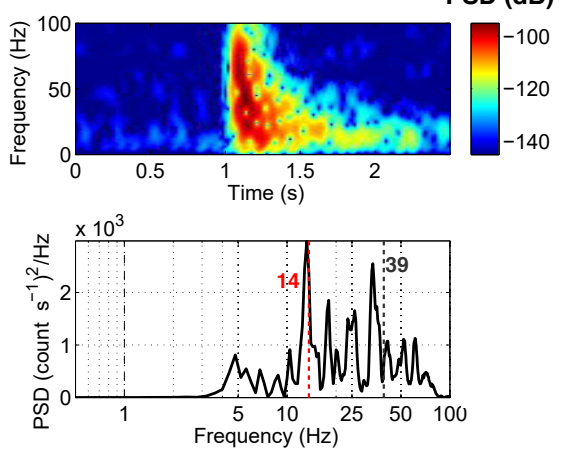

(c) Pont Bourquin
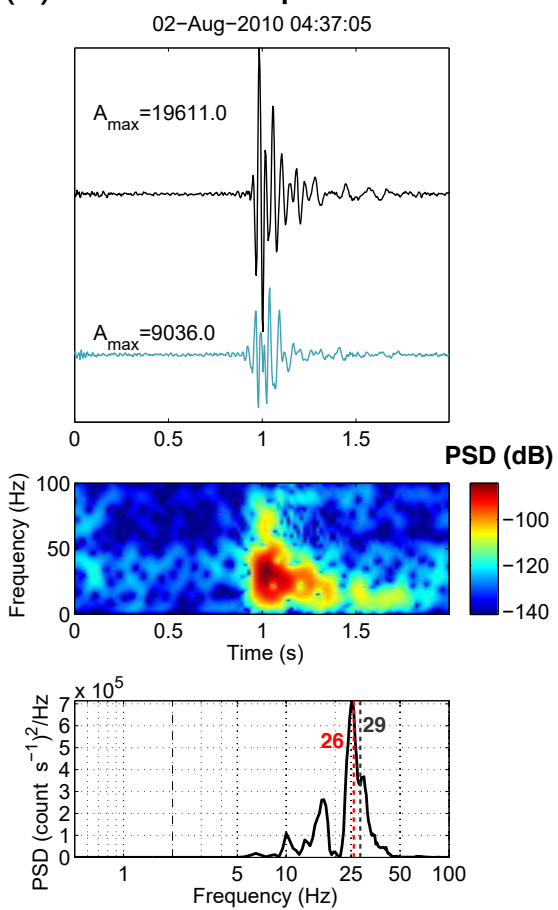

(f) Slumgullion
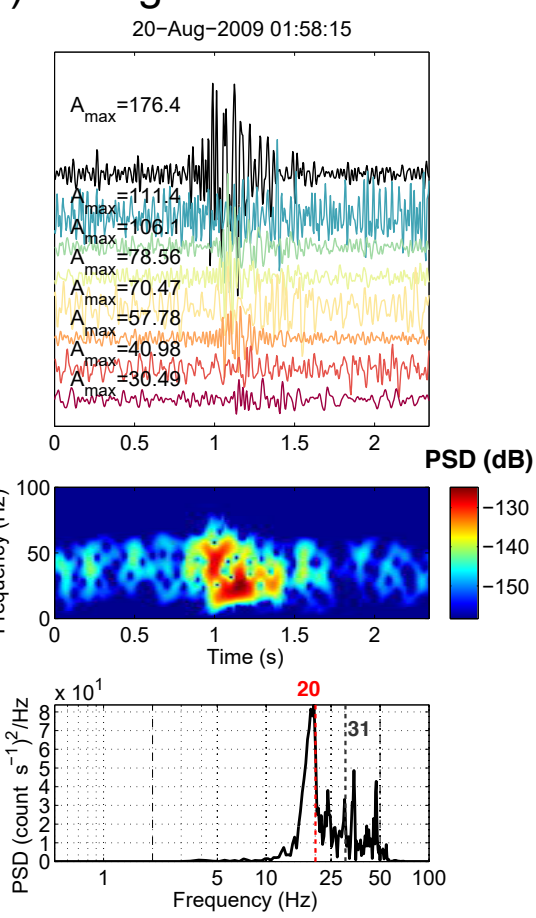

Figure 7. High-frequency slopequakes recorded at the (a) Super-Sauze (Provost et al., 2017a), (b) Séchilienne (Helmstetter et al., 2011; RESIF/OMIV, 2015), (c) Pont Bourquin, (d) La Clapière, (e) Aaknes and (f) Slumgullion (Gomberg et al., 2011) slopes. See Fig. 2 for a description of the figure. Note that for the Slumgullion signals (f), the amplitudes are expressed in counts. 
(a) Pechgraben
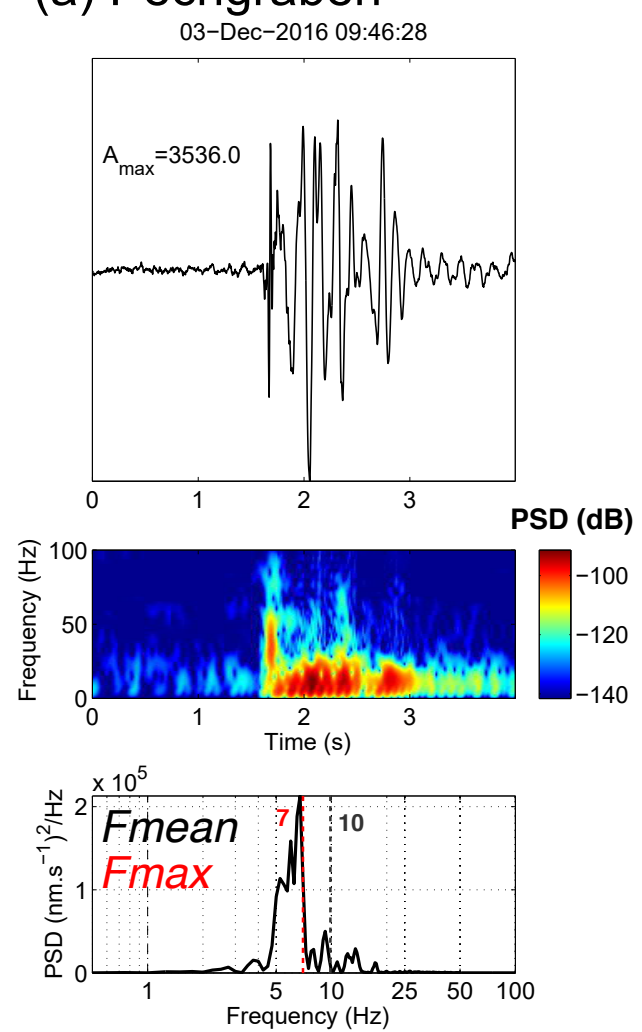

(b) Super-Sauze

10-Nov-2013 01:53:53
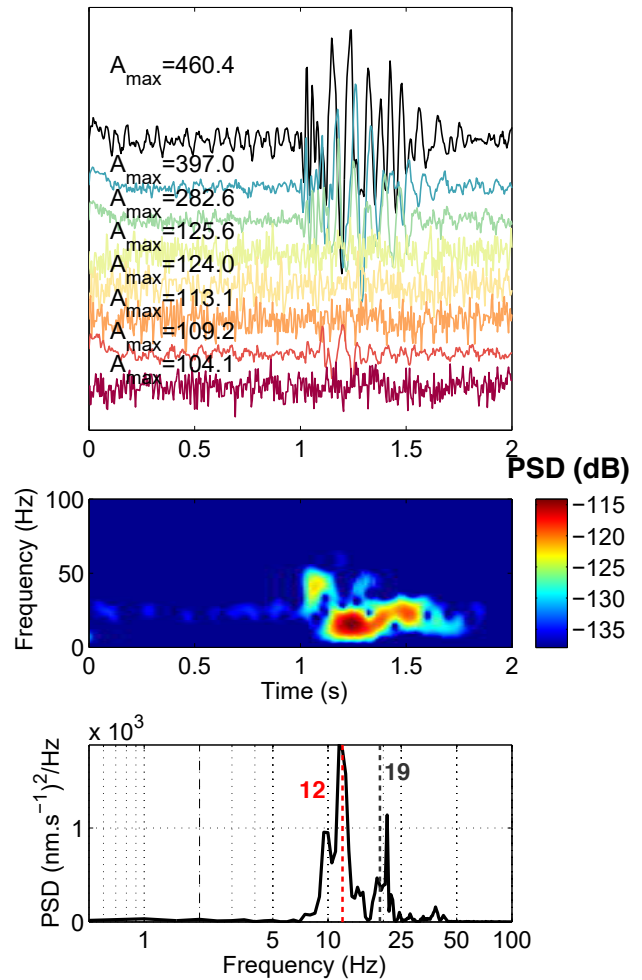

Figure 8. Hybrid slopequake recorded at the (a) Pechgraben and (b) Super-Sauze landslide. See Fig. 2 for a description of the figure.

ticular frequency content or precursory events. These additional characteristics change the possible interpretation of the sources. Consequently, these signals are gathered in the class "complex slopequake". Three different subclasses are proposed:

- Slopequake with precursors (Fig. 9): The third class of short duration signals are similar to the slopequake signals but are preceded by a precursory signal of smaller amplitude (Fig. 9). The content of the precursory signal ranges from 5 to $100 \mathrm{~Hz}$ depending on the site and is slightly lower than the highest frequency generated by slopequake-like event. The precursory arrival lasts up to $1.2 \mathrm{~s}$ in the presented examples and no clear phases are detected. The frequency content ranges from 5 to $100 \mathrm{~Hz}$ but varies significantly at each site. At all sites, the amplitude of the signal is significantly higher for one of the sensor (3 to 50 times higher) when considering vertical traces. The precursory signal is buried in the noise at the sensors with lowest amplitudes and the signal is similar to a LF-SQ. Such events have never been documented to our knowledge. They are likely to be generated by a strong and local source located in the very close vicinity of one of the sensors $(<10 \mathrm{~m})$ due to the maximal amplitude $\left(>10^{5} \mathrm{~nm} \mathrm{~s}^{-1}\right)$ and the rapid decrease in the amplitude recorded by the other sensors. Although the signal is similar to certain earthquakes (the precursory signals interpreted as $\mathrm{P}$-wave arrivals and the strong arrivals as surface waves), no earthquake location can explain the signal recorded at the time these events are recorded. Their occurrence in the nighttime makes a human activity unlikely to be the source. The most probable source would then be the detachment of a single block and its fall in the vicinity to one of the sensors. This kind of precursory signal is observed for some rockfalls (Fig. 3a) and at a the Saint-Martin-leVinoux quarry (France; Helmstetter et al., 2011). At the Saint-Martin-le-Vinoux underground quarry, the duration between the detachment and the signal impact is well correlated to the room height. This interpretation is coherent with the drop of amplitude before the more energetic event at the Chamousset rock column (Fig. 9c), where a progressive decrease in the precursory signal is observed. However, at the other sites (Fig. 9a, b) such a decrease is not present. The 1-second-long precursory signal has a constant amplitude and frequency content. Another interpretation could be that these precursory signals are a succession of overlapping slip or fracture events. The interpretation of these signals cannot be established with certainty and further analysis (i.e., loca- 
(a) Super-Sauze
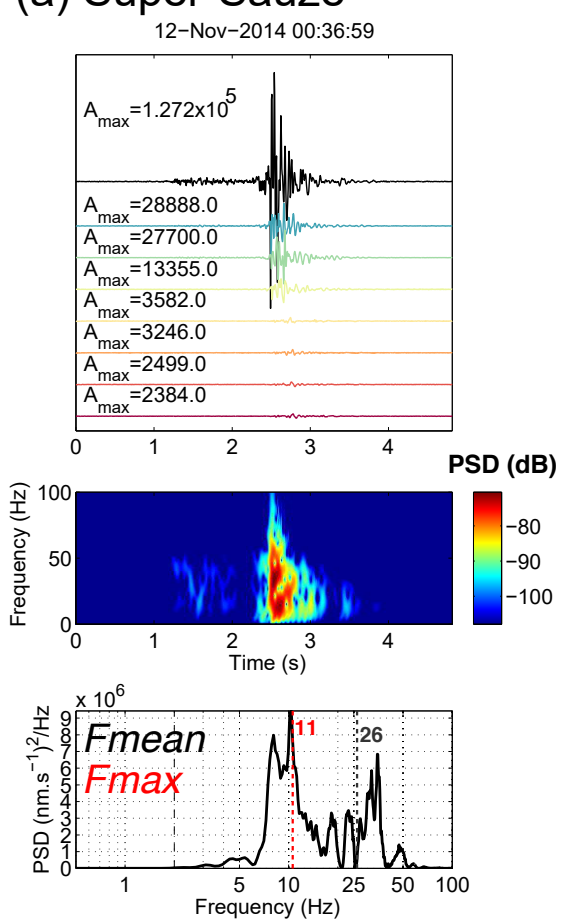

(b) Séchilienne

25-Oct-2010 17:18:17
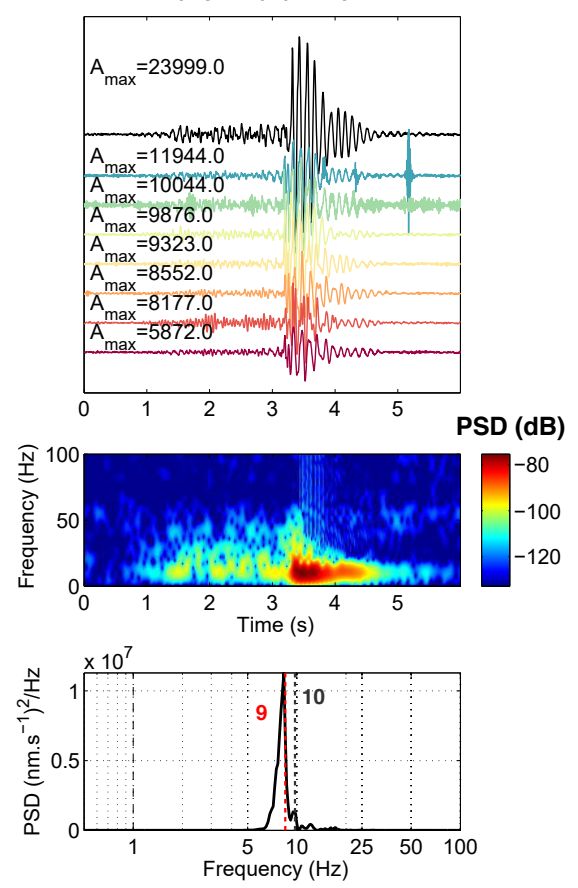

(c) Chamousset
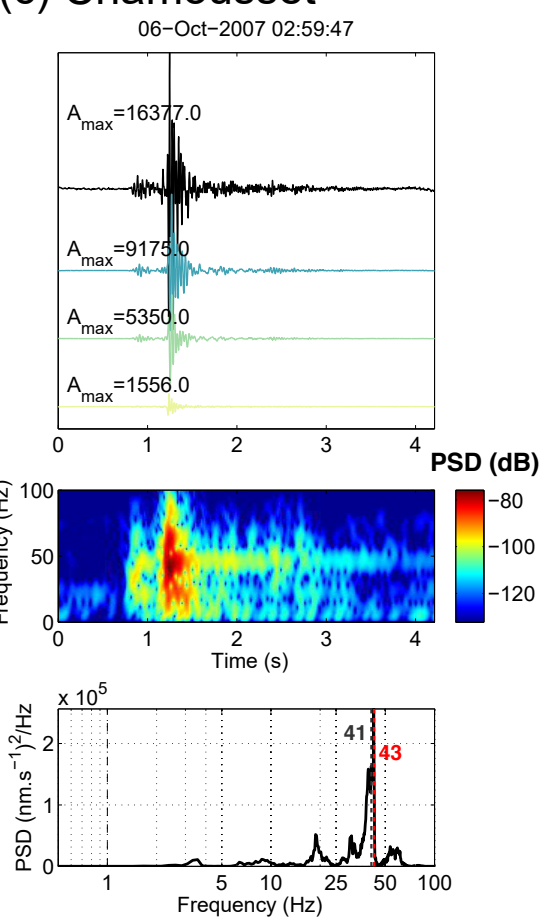

Figure 9. Examples of slopequakes with precursory events recorded at the (a) Super-Sauze, (b) Séchilienne and (c) Chamousset slopes. See Fig. 2 for a description of the figure.

tion, time of occurrence) and other examples are needed to discriminate the mechanism at work.

- Tremor-like slopequake (Fig. 10): The last class of short-duration signals often last between 1 and $5 \mathrm{~s}$ (Fig. 10). They present a symmetrical waveform ( $S=$ $50 \%$ ) with emergent arrivals and a slow decrease in the amplitude to the noise level. The frequency ranges from 5 to $25 \mathrm{~Hz}$. High frequencies may be briefly recorded in certain events (Fig. 10c). The maximal energy of the PSD corresponds to a frequency of 8 to $13 \mathrm{~Hz}$, while the mean energy corresponds to a frequency of 13 to $17 \mathrm{~Hz}$. No seismic phases are identified. The signal is not recorded by all the sensors even when the sensors are organized in small arrays with short inter-sensor distances $(<50 \mathrm{~m})$. Their waveforms and frequency content are similar to the one of the granular flows (Fig. 4). Small debris flows have been observed at La Clapière and Super-Sauze landslides and are likely to generate seismic waves; however, small debris flows are not observed at the Pas de l'Ours landslide when these kinds of seismic signals are recorded. Another possible source mechanism for such events may also be a very rapid succession $(<1 \mathrm{~s})$ of shear events along the basal or the side bounding strike-slip faults (Hawthorne and Ampuero, 2017). Further investigations are needed to an- alyze their occurrences over time and their location to confirm one or the other assumption.

\section{Discussion}

The proposed typology is summarized in Fig. 11. The approach consisted of comparing the datasets of different sites in order to identify the common features of the recorded seismic signals. Three main classes can be differentiated mainly from the length of the signals, the number of peaks and the duration of the autocorrelation. Figure 12 shows more examples of the signal variability for the sites where long seismic catalogs have been recorded (e.g., Aaknes, Chamousset, Séchilienne, Super-Sauze and La Clapière). Only the signals classified as rockfall, LF-SQ and HF-SQ are presented because fewer events of the other classes are present in the investigated datasets. The signal features are in good agreement with the defined classes proposed in the present classification (Fig. 11). In general, narrow variability is observed on the feature values among the different sites and consequently, the observed features are likely associated with the source mechanism.

However, some variability exists for rockfall events. Indeed, the volume of the blocks and possible breaks control the frequency content and the autocorrelation duration while the height of the scarp will play a significant role in the du- 
(a) Super-Sauze
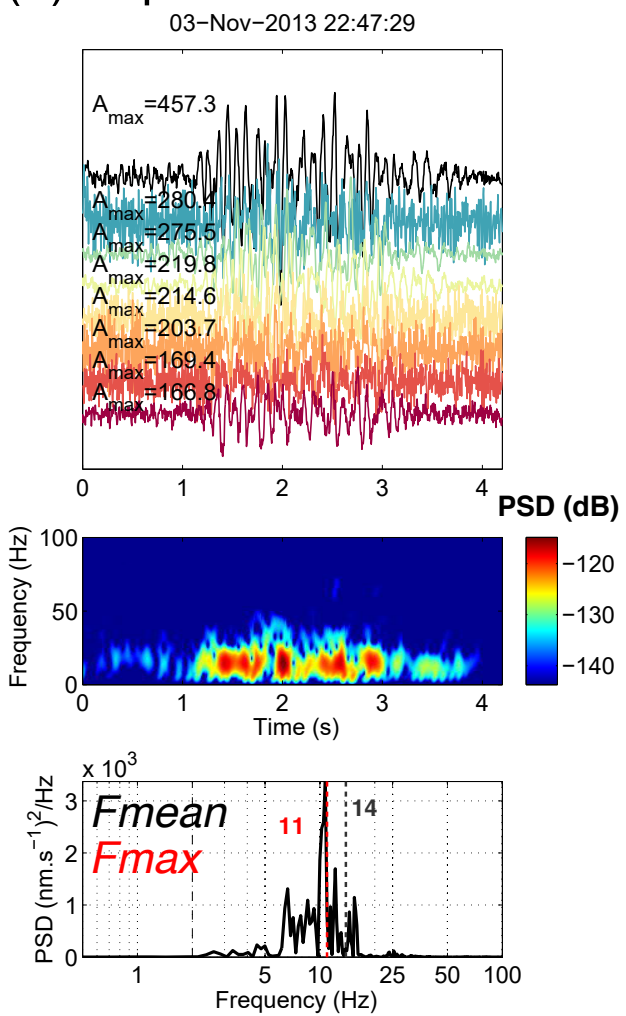

(c) Super-Sauze
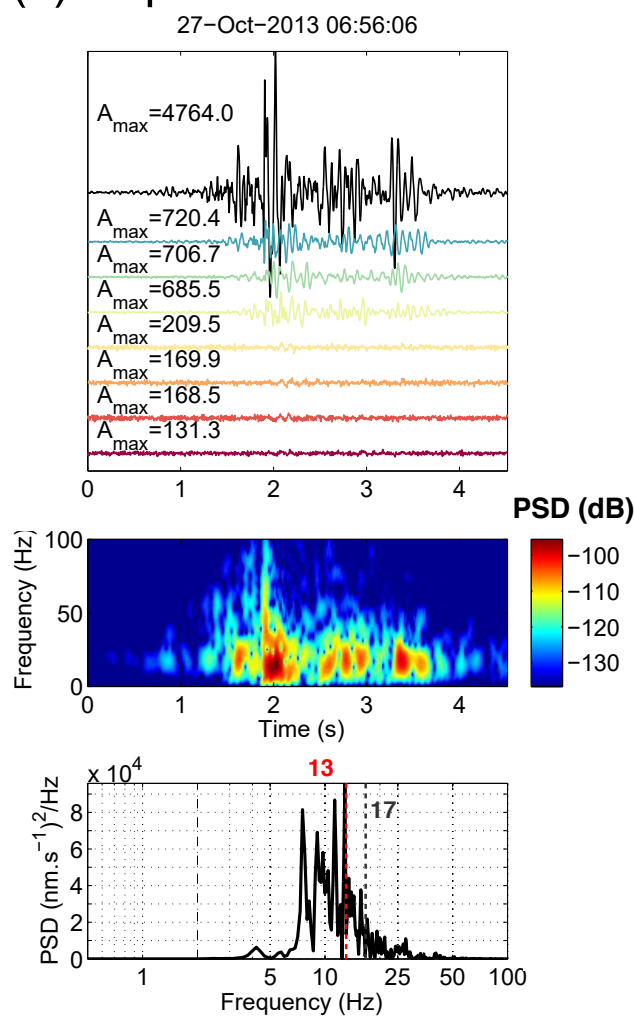

(b) La Clapière
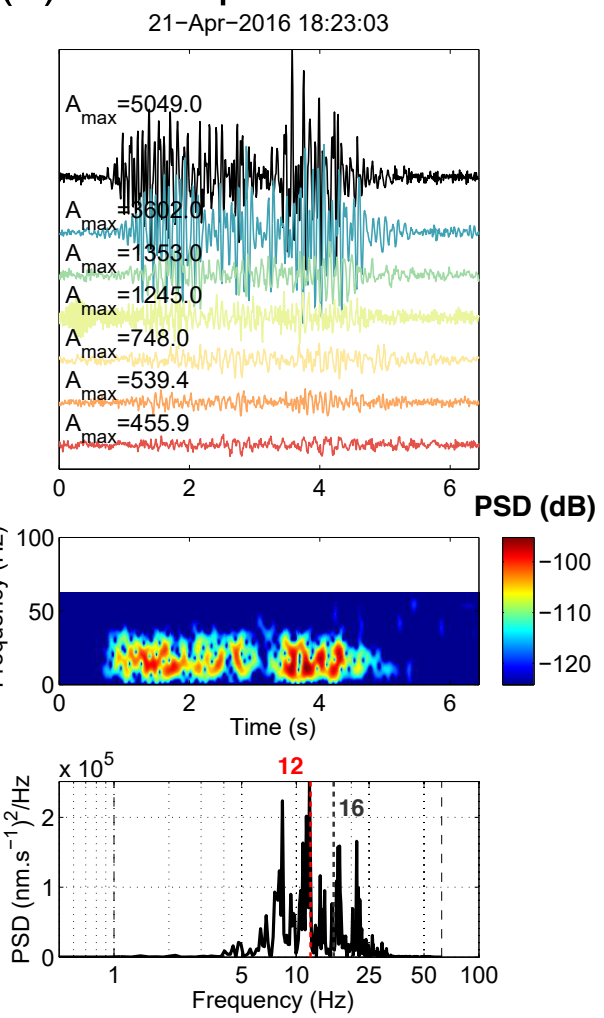

(d) Aiguilles-Pas de l'Ours 06-May-2017 22:47:47
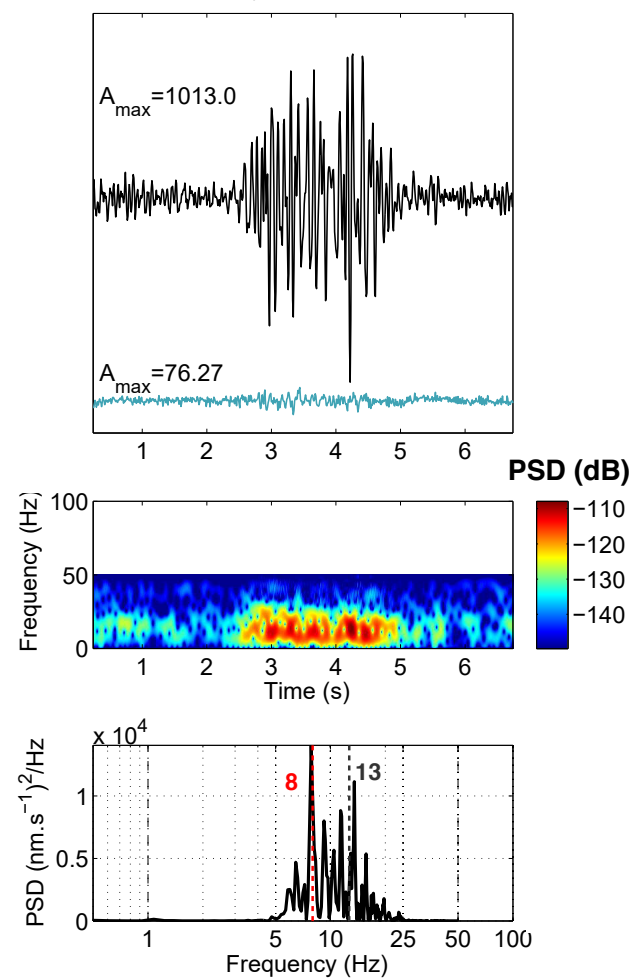

Figure 10. Examples of tremor-like slopequakes recorded at the (a, c) Super-Sauze, (b) La Clapière and (d) Aiguilles-Pas de l'Ours slopes. See Fig. 2 for a description of the figure. 
(a)

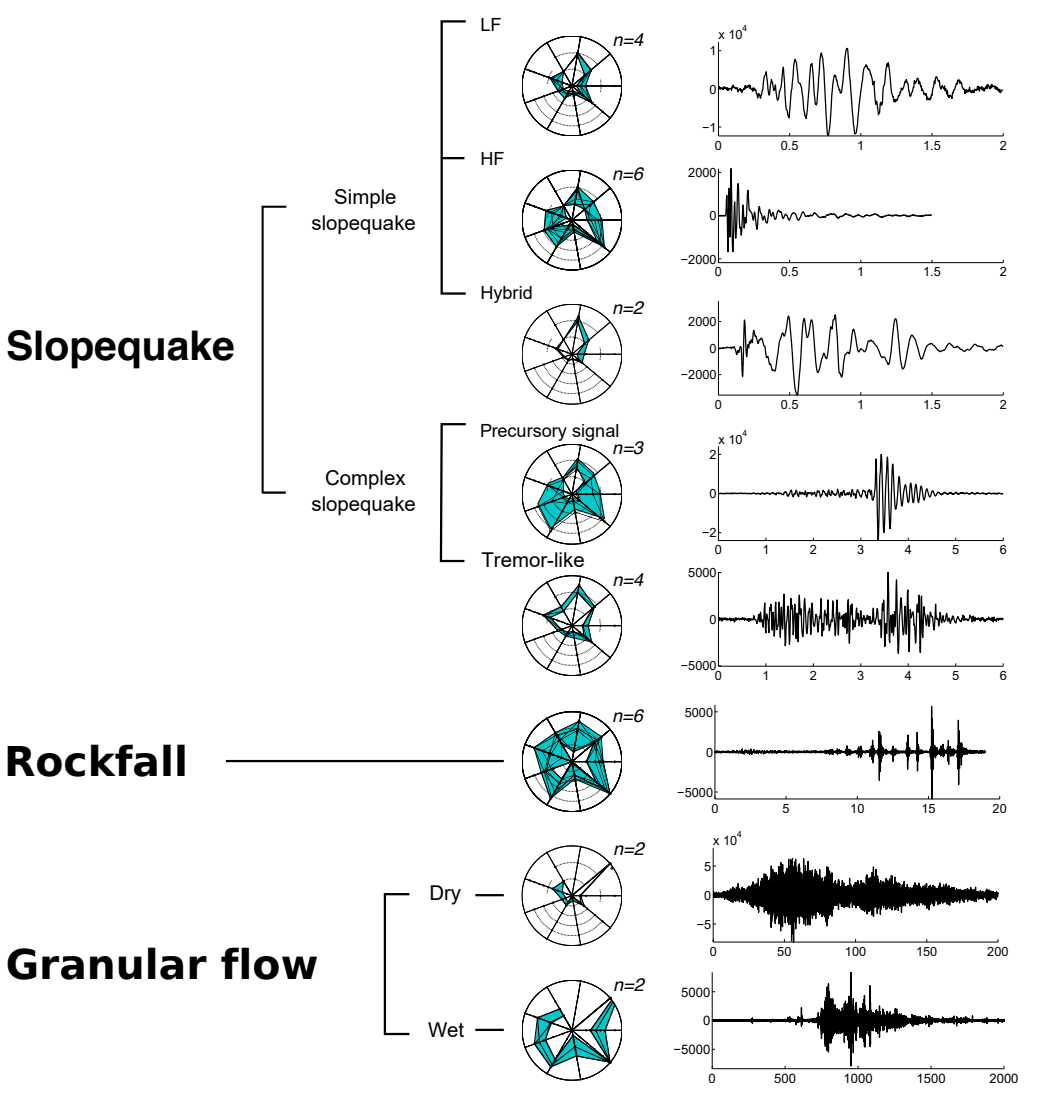

(b)

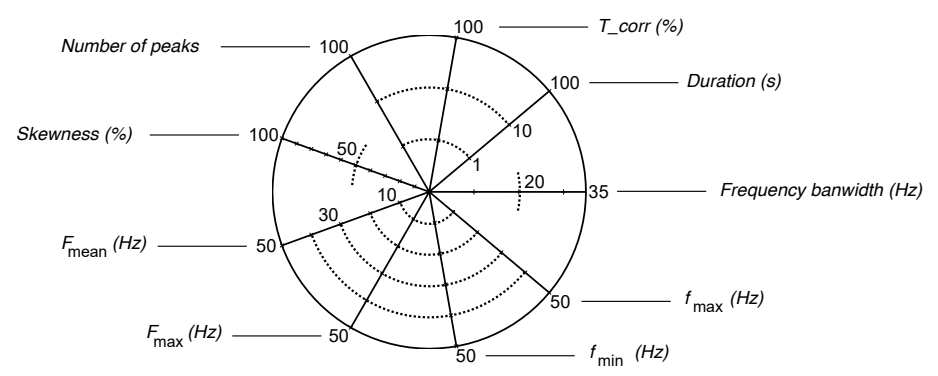

Figure 11. (a) Summary of the proposed classification with plots of the attributes for the examples presented in the precedent figures and an example waveform for each class. The convention for the attribute plot is presented in (b); $n$ being the number of seismic signals examples used to plot the feature diagram.

ration of the event. Depending on the site, rockfall signals can have similar features to each other (e.g., Séchilienne, Fig. 12) suggesting a constant source mechanism or very different features suggesting the presence of different rockfall mechanisms and/or trajectories (e.g., Super-Sauze, Fig. 12). In the case of the Super-Sauze datasets, rockfall are characterized by a lack of energy in high frequencies due, in this case, to the distance between the seismic network and the scarp. Installation of additional sensors could be the easiest way to get rid of this variability. It must also be noted, that differentiating flow and fall signals may be challenging. Indeed, some of the events are very likely a mix of these two sources. Rockfalls of various blocks may generate granular flows with metric block impacts, both overlapping in the recorded seismic signals. Presence of metric rocks is also observed in debris-flow-prone torrents; for this type of event, the block impacts within the mass flows are recorded in the seismic signals (Burtin et al., 2016).

Our analysis does not allow us, at this stage, to conclude whether the frequency content of the simple slopequakes is associated with the source mechanism because complete catalogs differentiating between HF-SQ and LF-SQ are not yet available. Colombero et al. (2018) suggested that HF-SQs are the dominant class of slopequake at the Madonna del Sasso 

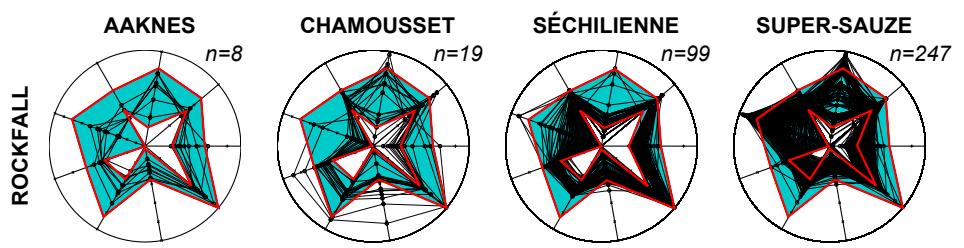

LA CLAPIÈRE
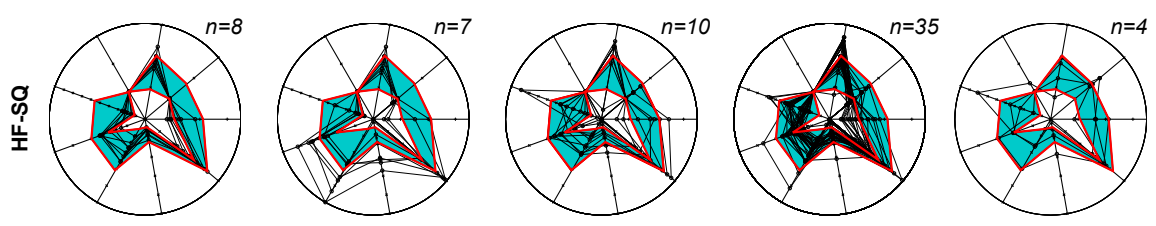

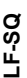
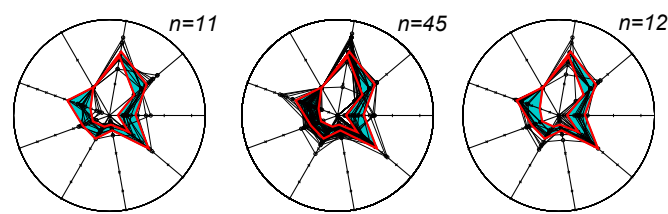

Figure 12. Variability in the signal features of classes "rockfall", "HF-SQ" and "LF-SQ" for five different sites: Aaknes, Chamousset, Séchilienne, Super-Sauze and La Clapière. The axes of the star diagrams are the same as in Fig. 11.

cliff (hard rock) and were generated by thermal cracking, while LF-SQs associated with frictional sliding are less frequent. Although we did not investigate the whole dataset, no LF-SQs were provided at the Aaknes or Chamousset hardrock cliffs (Fig. 12), while LF-SQs are recorded at the La Clapière and Séchilienne hard-rock slides: (Fig. 12). This observation seems to confirm the results of Colombero et al. (2018). However, further comparison of the occurrence of the different slopequakes at specific sites in space and time must be done to improve the comprehension of these sources and confirm this statement.

Harmonic signals have also been documented at the Pechgraben and Super-Sauze landslides (Vouillamoz et al., 2018). These signals last from 1 to $5 \mathrm{~s}$ and may repeat during minute-long sequences. The proposed interpretation includes hydro-fracturing or repetitive swarms of microearthquakes (Vouillamoz et al., 2018), while Gomberg et al. (2011) hypothesized that these kinds of signals were caused by trapped waves along the side-bounding strike-slip fault generated by shear events. In the investigated datasets, similar signals are recorded at the La Clapière and the Aiguilles landslides with a fundamental frequency of $8 \pm 1 \mathrm{~Hz}$ (Fig. 13b, c). At the Séchilienne landslide, harmonic signals are also detected (Fig. 13d), mostly during the day, with different resonant frequencies between 2 and $12 \mathrm{~Hz}$. Similar signals are observed at the Slumgullion and Super-Sauze sites but without clear harmonics in the PSD (Fig. 13e, f). The presence of pipes and drains on or in the vicinity of these sites could also explain the origin of these signals justifying that these signals are not included in the slopequake class as they may not be generated by a slope deformation process. The location of the source, the distribution of the amplitude, the stability of the fundamental frequency and the daily temporal occurrence of the source supports this assumption. Systematic location of these events is needed to determine if they must be integrated or not in the general typology in the case that they are generated by fluid resonance in fractures.

For certain signals, the coda is dominated by resonance frequencies (Figs. 3d, 9c) at high frequencies (i.e., 20 and $43 \mathrm{~Hz}$ ), and well observed in the spectrogram of the signal. The resonance is not present before the beginning of the signal and hence can not be due to anthropogenic noise (i.e., motors). In the case of Chamousset cliff, Levy et al. (2011) explained the presence of this monochromatic coda by the resonance of the rock column after the occurrence of the rock bridge breakage. At Super-Sauze, a similar resonant coda is observed at the end of certain rockfalls (Fig. 4d). Considering the distance between the main scarp and the seismic arrays $(>300 \mathrm{~m})$, and the absence of a large fracture on the scarp, the occurrence of this kind of resonance is very surprising in this case. This signal feature could also result from the wave propagation (i.e., trapped waves).

No long-lasting tremors are presented in this study. Schöpa et al. (2018) recorded a tremor with gliding before the occurrence of the Askja caldera landslide. Similar tremors have been found on the Whillans ice stream in Antarctica during slow slip events (Paul Winberry et al., 2013; Lipovsky and Dunham, 2016), which repeat twice a day with a slip of about $10 \mathrm{~cm}$ lasting for about $20 \mathrm{~min}$. Therefore, such signals may also occur during the nucleation phase of landslide failure. The question remains if they are not observed because landslide acceleration is aseismic due to high pore fluid pressure (Scholz, 1998) or low normal stress at the subsurface of the slope.

Difficulties still arise in providing an exhaustive description and interpretation of all the sources from the simple anal- 
(a) Pechgraben
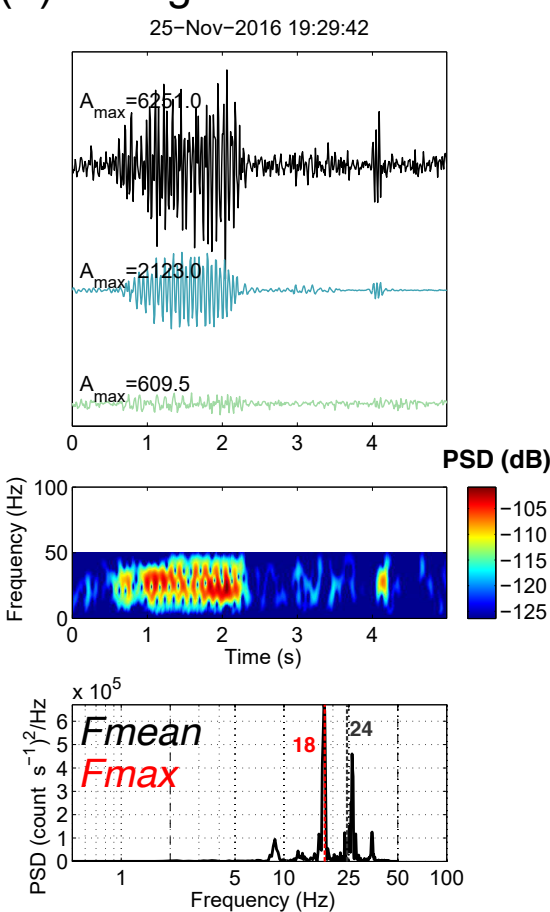

(d) Séchilienne
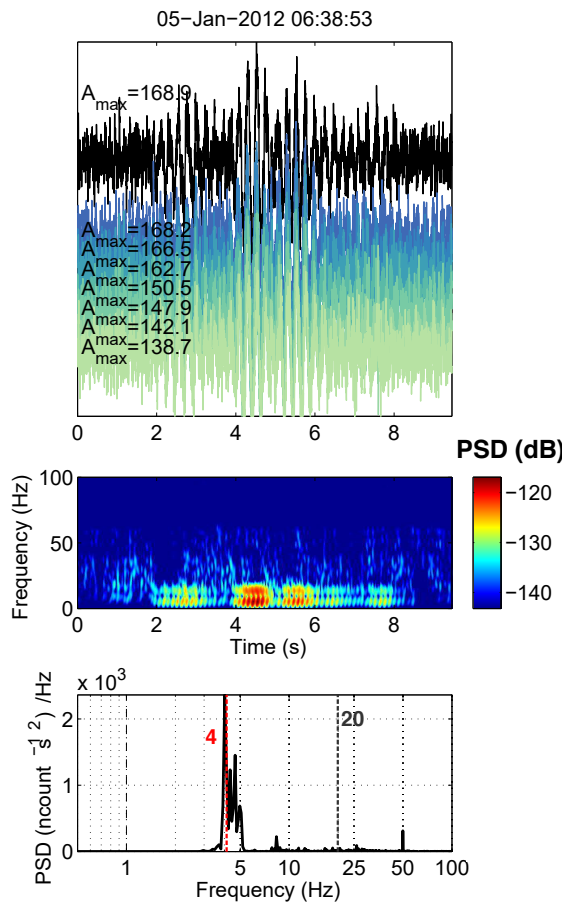

(b) La Clapière
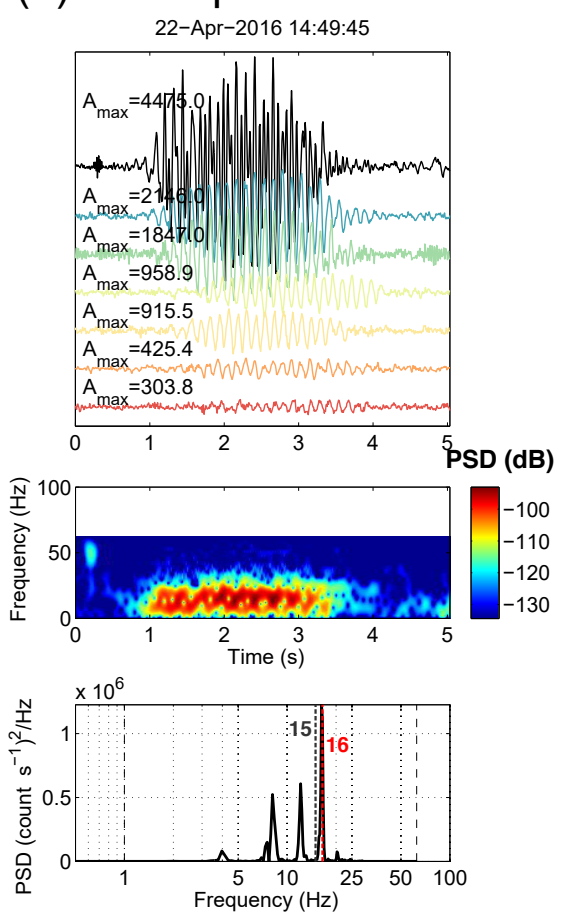

(e) Slumgullion
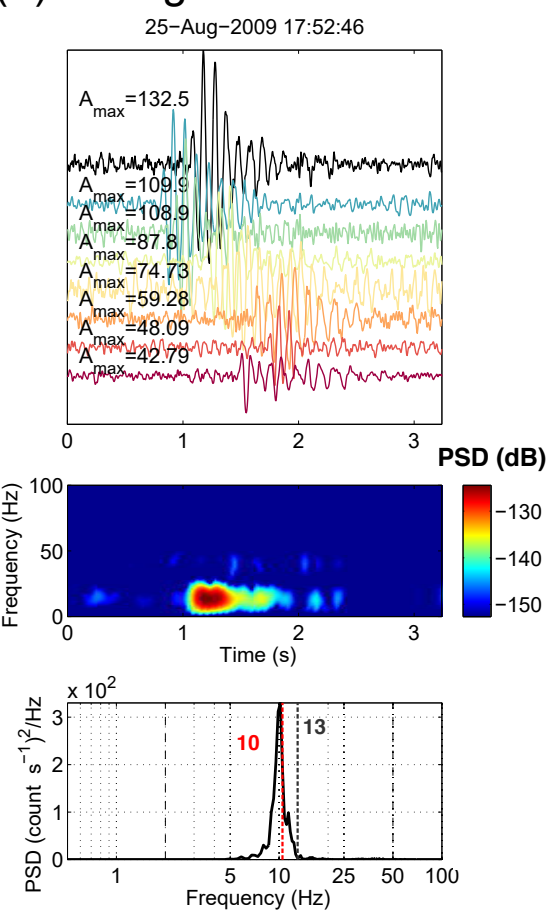

(c) Aiguilles-Pas de l'Ours
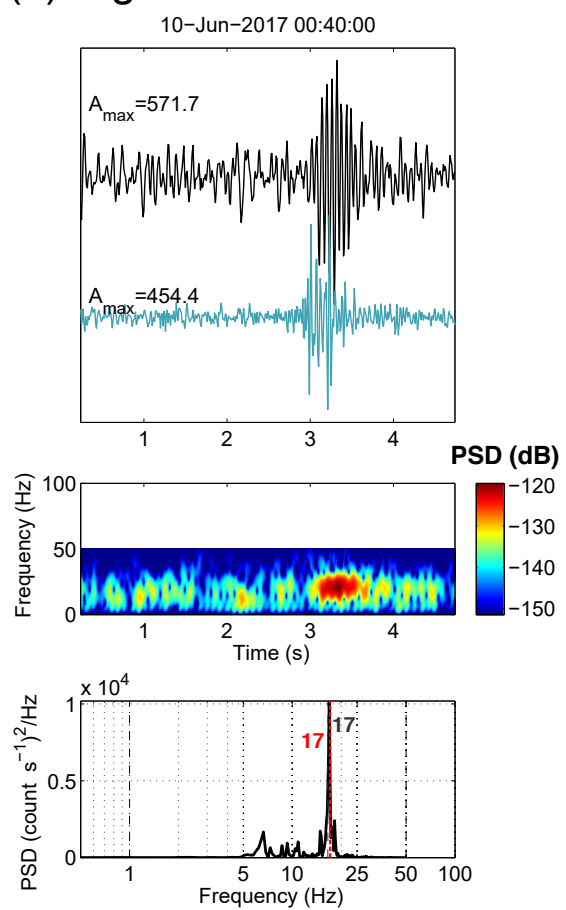

(f) Super-Sauze
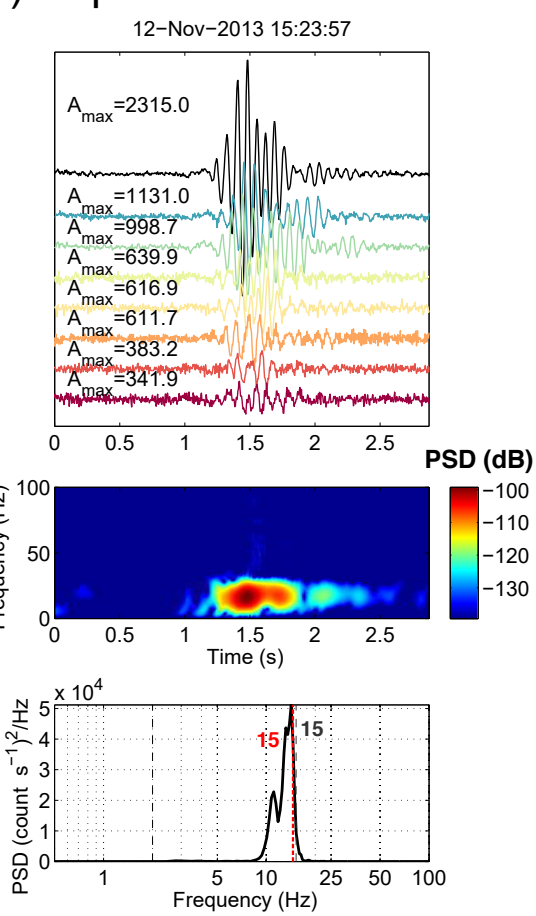

Figure 13. Examples of pure harmonic signals recorded at the (a) Pechgraben, (b) La Clapière, (c) Aiguilles-Pas de l'Ours, (d) Séchilienne, (e) Slumgullion (Gomberg et al., 2011) and (f) Super-Sauze slopes. See Fig. 2 for a description of the figure. Note that for the Slumgullion signals (e), the amplitudes are expressed in counts. 
ysis of the proposed signal features, particularly those generating short-duration signals, in particular for the classes discriminated by the frequency content such as LF-SQ and HFSQ. The ambiguity between propagation effect and source mechanisms prevents further interpretation due to several limitations. Firstly, the location of the sources remain difficult to establish due to the complexity of some of the signals (Gomberg et al., 2011; Lacroix and Helmstetter, 2011; Tonnellier et al., 2013; Provost et al., 2018), the size of the instrumented sites and the complexity of the underground structure that influences the polarization of the waves (Neuberg et al., 2000) and the sensors (ie. number, location and type: $1 \mathrm{C} / 3 \mathrm{C}$ sensor) installed close to the unstable slopes (Godano et al., 2009). The location of the epicenter of most of the events seems coherent with the instability deformation field at the surface (Helmstetter and Garambois, 2010; Levy et al., 2011; Walter et al., 2013b; Provost et al., 2018), although resolving dispersion and 3-D heterogeneities of the velocity fields currently prevents us from inferring the depth of the events and their focal mechanisms. Secondly, a complementary approach to explain the origin of the sources is the analysis of their occurrence with respect to surface or basal displacement and monitoring of the water content and pore fluid pressures. It requires both exhaustive catalogs of landslide seismicity over long time periods and continuous and distributed datasets of displacements and pore fluid pressures, which remain challenging to acquire. Finally, in addition to the characteristics of seismic signals, further information on the sources processes can be obtained from the distribution of the events in time, space and size. Events that occur regularly in time with similar amplitudes are likely associated with the repeated failure of an asperity surrounded by aseismic slip, for instance, at the base of a glacier (Helmstetter et al., 2015a) or of a landslide (Yamada et al., 2016a; Poli, 2017). Signal amplitudes and recurrence times often display progressive variations in time. In contrast, events that are clustered in time and space, with a broad distribution of energies, are more likely associated with the propagation of a fracture (Helmstetter et al., 2015b). The daily distribution of an events time can also be helpful to identify anthropogenic sources, which occur mostly during the day. In contrast, natural events are more frequently detected at night, when the noise level is lower.

Simulations and models are also required to explain the current observations. Indeed, experimental results suggest an increase in AEs correlated with an increase in the slope velocity (Smith et al., 2017) or an increase in AE due to the creation of the rupture area (Lockner et al., 1991). Acceleration of pre-existing rupture surface(s) seems to be the mechanism responsible for the seismicity recorded before large rockslide collapse. Yamada et al. (2016a) and Poli (2017) argued that the high correlation between the repetitive events could only be explained by stick-slip movement of the locked section(s), while a cracking process would imply a migration of the location of the events and a change in the events waveforms. Schöpa et al. (2018) argued that the presence of gliding frequencies could only be produced by similar sources and hence close location. On the contrary, in the case of the Mesnil-Val column, Senfaute et al. (2009) interpreted the evolution from high-frequency to low-frequency events as the progressive formation of the rupture surface followed by the final rupture process immediately before the column collapse, where both tensile cracks and shearing motion on the created rupture are generated.

\section{Conclusions}

Over the last few decades, numerous studies have recorded seismic signals generated by various types of landslides (i.e., slide, topple, fall and flow), for different kinematic regimes and rock/soil media. These studies demonstrated the added value of analyzing landslide-induced MS to improve our understanding of the mechanisms and to progress in the forecast of landslide evolution.

In this work we propose a review of the endogenous seismic sources generated by the deformation of unstable slopes. A dataset of 14 slopes is gathered and analyzed. Each of the sources are described by nine quantitative features of the recorded seismic signals. Those features provide distinct characteristics for each type of source. A library of relevant signals recorded at relevant sites is shared as supplementary material. We propose three main classes "slopequake", "rockfall" and "granular flow" to describe the main type of deformation observed on the slopes. Slopequakes are related to shearing or fracturing processes. This family exhibits the most variability due to the complexity of the sources. These variations are likely to be generated by different source mechanisms. "Rockfall" and "granular flow" classes are associated with mass propagation on the slope surface. They are distinguishable by the number of peaks clearly identified in the seismic signals.

Presently, several descriptions of the seismic sources are proposed for each study case. We believe that a standard typology will allow researchers to discuss and compare seismic signals recorded at many unstable slopes. We encourage future studies to use and possibly enrich the proposed typology. This also requires publication of the datasets and/or catalogs to progress towards a common interpretation. Recently, organizations such as the United States Geological Survey (USGS) or the French Landslide Observatory (OMIV) have started this work (RESIF/OMIV, 2015).

Recent arrivals on the market of relatively cheap and autonomous seismometers (e.g., ZLand ${ }^{\circledR}$ node systems, Raspberry Shake systems) will allow the deployment of denser seismic networks of 3C sensors. The latter will certainly improve the location accuracy and enable inversion of the focal mechanism of the sources. Moreover, the recent operational applications of ground-based SAR (synthetic aperture radar) and terrestrial lidar technologies for monitoring purposes 
shows their relevance to monitor distributed surface displacements. Ongoing monitoring on several landslides combining those innovative approaches will certainly help to associate slopequake events to deformation processes (Dietze et al., 2017b; RESIF/OMIV, 2015; Provost et al., 2017b).

The proposed typology will help to constrain the design of new models to confirm the assumptions on the nature and the properties of the seismic sources. This will be particularly important for (1) explaining the variability of the slopequake sources observed at the sites, (2) progressing in the physical understanding of the slopequake sources, and (3) ascertaining the spatiotemporal variations in the seismic activity observed at some unstable slopes in relation with their deformation, as well as with external forcings such as intense rainfalls and earthquakes.

Data availability. The library of the endogenous seismic signals recorded at the sites and described in the paper is shared as supplementary material. The seismic data are shared in the OMIV website: http://www.ano-omiv.cnrs.fr/ressources/library.

Competing interests. The authors declare that they have no conflict of interest.

Special issue statement. This article is part of the special issue "From process to signal - advancing environmental seismology". It is a result of the EGU Galileo conference, Ohlstadt, Germany, 6-9 June 2017.

Acknowledgements. This work was carried with the support of the French National Research Agency (ANR) through the projects HYDROSLIDE "Hydrogeophysical Monitoring of Clayey Landslides", SAMCO "Society Adaptation to Mountain Gravitational Hazards in a Global change Context" and TIMES "High-performance Processing Techniques for Mapping and Monitoring Environmental Changes from Massive, Heterogeneous and High Frequency Data Times Series". Additional support by the Open Partial Agreement "Major Hazards" of the Council of Europe through the project "Development of Cost-effective Ground-based and Remote Monitoring Systems for Detecting Landslide Initiation" was available. The continuous seismic data were provided by the Observatoire Multi-disciplinaire des Instabilités de Versant (OMIV) (RESIF/OMIV, 2015). Some seismic signals analyzed were acquired with seismometers belonging to the French national pool of portable seismic instruments SISMOB-RESIF. The authors thank J. Gomberg for access to the data of the Slumgullion slope, constructive discussions and review of the early version of this paper as well as Nick Rosser and Emma Vann Jones for access to the data of the North Yorkshire cliff. The authors also thank Naomi Vouillamoz (University of Stuttgart) and Pascal Diot (ONF-RTM) for helping with the data acquisition at, respectively, the Pechgraben site and the Aiguilles-Pas de l'Ours site. The authors gratefully acknowledge Velio Coviello and Wei-An Chao for their careful reviews and thorough comments which helped improving the manuscript.

Edited by: Jens Turowski

Reviewed by: Velio Coviello, Wei-An Chao, and one anonymous referee

\section{References}

Abancó, C., Hürlimann, M., Fritschi, B., Graf, C., and Moya, J.: Transformation of ground vibration signal for debris-flow monitoring and detection in alarm systems, Sensors, 12, 4870-4891, 2012.

Abancó, C., Hürlimann, M., and Moya, J.: Analysis of the ground vibration generated by debris flows and other torrential processes at the Rebaixader monitoring site (Central Pyrenees, Spain), Nat. Hazards Earth Syst. Sci., 14, 929-943, https://doi.org/10.5194/nhess-14-929-2014, 2014.

Allen, R.: Automatic phase pickers: Their present use and future prospects, Bull. Seis. Soc. Am., 72, S225-S242, 1982.

Allstadt, K. and Malone, S. D.: Swarms of repeating stickslip icequakes triggered by snow loading at Mount Rainier volcano, J. Geophys. Res., 119, 1180-1203, https://doi.org/10.1002/2014JF003086, 2014.

Amitrano, D., Grasso, J. R., and Senfaute, G.: Seismic precursory patterns before a cliff collapse and critical point phenomena, Geophys. Res. Lett., 32, 108314, https://doi.org/10.1029/2004GL022270, 2005.

Amitrano, D., Arattano, M., Chiarle, M., Mortara, G., Occhiena, C., Pirulli, M., and Scavia, C.: Microseismic activity analysis for the study of the rupture mechanisms in unstable rock masses, Nat. Hazards Earth Syst. Sci., 10, 831-841, https://doi.org/10.5194/nhess-10-831-2010, 2010.

Arattano, M. and Moia, F.: Monitoring the propagation of a debris flow along a torrent, Hydrol. Sci. J., 44, 811-823, 1999.

Arattano, M., Abancó, C., Coviello, V., and Hürlimann, M.: Processing the ground vibration signal produced by debris flows: the methods of amplitude and impulses compared, Comput. Geosci., 73, 17-27, https://doi.org/10.1016/j.cageo.2014.08.005, 2014.

Arattano, M., Covellio, V., Abancó, C., Hürlimann, M., and McArdell, B. W.: Methods of Data Processing for Debris Flow Seismic Warning, Int. J. Ero. Cont. Eng., 9, 114-121, 2016.

Benson, P. M., Vinciguerra, S., Meredith, P. G., and Young, R. P.: Laboratory Simulation of Volcano Seismicity, Science, 322, 249-252, https://doi.org/10.1126/science.1161927, 2008.

Berti, M., Genevois, R., LaHusen, R., Simoni, A., and Tecca, P.: Debris flow monitoring in the Acquabona watershed on the Dolomites (Italian Alps), Phys. Chem. Earth Pt. B, 25, 707-715, 2000.

Bessason, B., Eirísson, G., Thorarinsson, O., Thórarinsson, A., and Einarsson, S.: Automatic detection of avalanches and debris flows by seismic methods, J. Glaciol., 53, 461-472, https://doi.org/10.3189/002214307783258468, 2007.

Biescas, B., Dufour, F., Furdada, G., Khazaradze, G., and Suriñach, E.: Frequency Content Evolution of Snow Avalanche Seismic Signals, Surv. Geophys., 24, 447-464, https://doi.org/10.1023/B:GEOP.0000006076.38174.31, 2003.

Bièvre, G., Helmstetter, A., Lacroix, P., Baillet, L., Langlais, M., Vial, B., Voisin, C., Larose, E., and Jongmans, D.: Réactiva- 
tion du glissement-coulé d'Harmalière (Isère, France), Journées Aléas Gravitaires, Besançon, France, 2017.

Bottelin, P., Levy, C., Baillet, L., Jongmans, D., and Gueguen, P.: Modal and thermal analysis of Les Arches unstable rock column (Vercors massif, French Alps), Geophys. J. Int., 194, 849-858, https://doi.org/10.1093/gji/ggt046, 2013a.

Bottelin, P., Jongmans, D., Baillet, L., Lebourg, T., Hantz, D., Levy, C., Roux, O. L., Cadet, H., Lorier, L., Rouiller, J.-D., Turpin, J., and Darras, L.: Spectral Analysis of Prone-to-fall Rock Compartments using Ambient Vibrations, J. Environ. Eng. Geophys., 18, 205-217, https://doi.org/10.2113/JEEG18.4.205, 2013b.

Bottelin, P., Jongmans, D., Daudon, D., Mathy, A., Helmstetter, A., Bonilla-Sierra, V., Cadet, H., Amitrano, D., Richefeu, V., Lorier, L., Baillet, L., Villard, P., and Donzé, F.: Seismic and mechanical studies of the artificially triggered rockfall at Mount Néron (French Alps, December 2011), Nat. Hazards Earth Syst. Sci., 14, 3175-3193, https://doi.org/10.5194/nhess14-3175-2014, 2014.

Brückl, E., Brunner, F. K., Lang, E., Mertl, S., Müller, M., and Stary, U.: The Gradenbach Observatory - monitoring deepseated gravitational slope deformation by geodetic, hydrological, and seismological methods, Landslides, 10, 815-829, https://doi.org/10.1007/s10346-013-0417-1, 2013.

BRGM: Ecoute acoustique et microsismicité appliquée aux mouvements de terrain. Etat de l'art., Rapport BRGM R38659, BRGM, document annexe à la PG11., 1995.

Brodsky, E. E., Gordeev, E., and Kanamori, H.: Landslide basal friction as measured by seismic waves, Geophys. Res. Lett., 30, 2236, https://doi.org/10.1029/2003GL018485, 2003.

Brown, J. R., Beroza, G. C., Ide, S., Ohta, K., Shelly, D. R., Schwartz, S. Y., Rabbel, W., Thorwart, M., and Kao, H.: Deep low-frequency earthquakes in tremor localize to the plate interface in multiple subduction zones, Geophys. Res. Lett., 36, 119306, https://doi.org/10.1029/2009GL040027, 2009.

Brückl, E.: Large landslides with seismicity, Rock Mechanics and Engineering Volume 4: Excavation, Support and Monitoring, p. 365, 2017.

Burtin, A., Bollinger, L., Cattin, R., Vergne, J., and Nábĕlek, J. L.: Spatiotemporal sequence of Himalayan debris flow from analysis of high-frequency seismic noise, J. Geophys. Res., 114, F04009, https://doi.org/10.1029/2008JF001198, 2009.

Burtin, A., Hovius, N., Milodowski, D. T., Chen, Y.-G., Wu, Y.-M., Lin, C.-W., Chen, H., Emberson, R., and Leu, P.-L.: Continuous catchment-scale monitoring of geomorphic processes with a 2-D seismological array, J. Geophys. Res., 118, 1956-1974, 2013.

Burtin, A., Hovius, N., McArdell, B. W., Turowski, J. M., and Vergne, J.: Seismic constraints on dynamic links between geomorphic processes and routing of sediment in a steep mountain catchment, Earth Surf. Dynam., 2, 21-33, https://doi.org/10.5194/esurf-2-21-2014, 2014.

Burtin, A., Hovius, N., and Turowski, J. M.: Seismic monitoring of torrential and fluvial processes, Earth Surf. Dynam., 4, 285-307, https://doi.org/10.5194/esurf-4-285-2016, 2016.

Cadman, J. D. and Goodman, R. E.: Landslide Noise, Science, 158, 1182-1184, https://doi.org/10.1126/science.158.3805.1182, 1967.

Chen, Z., Stewart, R., Bland, H., and Thurston, J.: Microseismic activity and location at Turtle Mountain, Alberta, 16, 18, Con- sortium for Research in Elastic Wave Exploration Seismology, CREWES, University of Calgary, Canada, 2005.

Chouet, B.: Resonance of a fluid-driven crack: Radiation properties and implications for the source of long-period events and harmonic tremor, J. Geophys. Res., 93, 4375-4400, https://doi.org/10.1029/JB093iB05p04375, 1988.

Colombero, C., Comina, C., Vinciguerra, S., and Benson, P. M.: Microseismicity of an unstable rock mass: From field monitoring to laboratory testing, J. Geophys. Res.-Solid Earth, 123, 16731693, https://doi.org/10.1002/2017JB014612, 2018.

Coviello, V., Arattano, M., and Turconi, L.: Detecting torrential processes from a distance with a seismic monitoring network, Nat. Hazards, 78, 2055-2080, 2015.

Cruden, D. M. and Varnes, D. J.: Landslide types and processes, in: Landslide investigation and mitigation, edited by: Turner, A. K. and Schuster, R. L., Transportation Research Board Special Report, 36-71, National Academy of Sciences, Washington DC, 1996.

Curilem, G., Vergara, J., Fuentealba, G., Acuña, G., and Chacón, M.: Classification of seismic signals at Villarrica volcano (Chile) using neural networks and genetic algorithms, J. Volc. Geotherm. Res., 180, 1-8, 2009.

Dammeier, F., Moore, J. R., Haslinger, F., and Loew, S.: Characterization of alpine rockslides using statistical analysis of seismic signals, J. Geophys. Res., 116, F04024, https://doi.org/10.1029/2011JF002037, 2011.

Dammeier, F., Moore, J. R., Hammer, C., Haslinger, F., and Loew, S.: Automatic detection of alpine rockslides in continuous seismic data using Hidden Markov Models, J. Geophys. Res., 121, 351-371, 2016.

Deichmann, N., Ansorge, J., Scherbaum, F., Aschwanden, A., Bernard, F., and Gudmundsson, G. H.: Evidence for deep icequakes in an Alpine glacier, Ann. Glaciol., 31, 85-90, https://doi.org/10.3189/172756400781820462, 2000.

Deparis, J., Jongmans, D., Cotton, F., Baillet, L., Thouvenot, F., and Hantz, D.: Analysis of Rock-Fall and Rock-Fall Avalanche Seismograms in the French Alps, Bull. Seis. Soc. Am., 98, 17811796, https://doi.org/10.1785/0120070082, 2008.

Derode, B., Guglielmi, Y., De Barros, L., and Cappa, F.: Seismic responses to fluid pressure perturbations in a slipping fault, Geophys. Res. Lett., 42, 3197-3203, https://doi.org/10.1002/2015GL063671, 2015.

Dietze, M., Mohadjer, S., Turowski, J. M., Ehlers, T. A., and Hovius, N.: Seismic monitoring of small alpine rockfalls - validity, precision and limitations, Earth Surf. Dynam., 5, 653-668, https://doi.org/10.5194/esurf-5-653-2017, 2017a.

Dietze, M., Turowski, J. M., Cook, K. L., and Hovius, N.: Spatiotemporal patterns, triggers and anatomies of seismically detected rockfalls, Earth Surf. Dynam., 5, 757-779, https://doi.org/10.5194/esurf-5-757-2017, 2017b.

Dixon, N., Hill, R., and Kavanagh, J.: Acoustic emission monitoring of slope instability: development of an active waveguide system, Proceedings of the Institution of Civil Engineers - Geotech Eng., 156, 83-95, https://doi.org/10.1680/geng.2003.156.2.83, 2003.

Dixon, N., Spriggs, M. P., Smith, A., Meldrum, P., and Haslam, E.: Quantification of reactivated landslide behaviour using acoustic emission monitoring, Landslides, 12, 549-560, https://doi.org/10.1007/s10346-014-0491-z, 2015. 
Dixon, N., Smith, A., Flint, J. A., Khanna, R., Clark, B., and Andjelkovic, M.: An acoustic emission landslide early warning system for communities in low-income and middle-income countries, Landslides, https://doi.org/10.1007/s10346-018-0977$1,2018$.

Doi, I., Matsuura, S., Shibasaki, T., and Osawa, H.: in: Seismic measurements in a mudstone landslide area, 10th Asian Regional Conference of IAEG, 2015.

Ekström, G. and Stark, C. P.: Simple Scaling of Catastrophic Landslide Dynamics, Science, 339, 1416-1419, https://doi.org/10.1126/science.1232887, 2013.

Ekström, G. and Stark, C. P.: Simple scaling of catastrophic landslide dynamics, Science, 339, 1416-1419, https://doi.org/10.1126/science.1232887, 2013.

Fäh, D. and Koch, K.: Discrimination between Earthquakes and Chemical Explosions by Multivariate Statistical Analysis: A Case Study for Switzerland, Bull. Seis. Soc. Am., 92, 17951805, https://doi.org/10.1785/0120010166, 2002.

Farin, M., Mangeney, A., and Roche, O.: Fundamental changes of granular flow dynamics, deposition and erosion processes at high slope angles: insights from laboratory experiments, J. Geophys. Res., 119, https://doi.org/10.1002/2013JF002750, 2014.

Galgaro, A., Tecca, P. R., Genevois, R., and Deganutti, A. M.: Acoustic module of the Acquabona (Italy) debris flow monitoring system, Nat. Hazards Earth Syst. Sci., 5, 211-215, https://doi.org/10.5194/nhess-5-211-2005, 2005.

Godano, M., Regnier, M., Deschamps, A., Bardainne, T., and Gaucher, E.: Focal mechanisms from sparse observations by nonlinear inversion of amplitudes: method and tests on synthetic and real data, Bull. Seis. Soc. Am., 99, 2243-2264, 2009.

Gomberg, J., Bodin, P., Savage, W., and Jackson, M. E.: Landslide faults and tectonic faults, analogs?: The Slumgullion earthflow, Colorado, Geology, 23, 41-44, https://doi.org/10.1130/00917613(1995)023<0041:LFATFA>2.3.CO;2, 1995.

Gomberg, J., Schulz, W., Bodin, P., and Kean, J.: Seismic and geodetic signatures of fault slip at the Slumgullion Landslide Natural Laboratory, J. Geophys. Res., 116, https://doi.org/10.1029/2011JB008304, 2011.

Hammer, C., Beyreuther, M., and Ohrnberger, M.: A Seismic-Event Spotting System for Volcano Fast-Response Systems, Bull. Seis. Soc. Am., 102, 948-960, 2012.

Hammer, C., Ohrnberger, M., and Fäh, D.: Classifying seismic waveforms from scratch: a case study in the alpine environment, Geophys. J. Int., 192, 425-439, https://doi.org/10.1093/gji/ggs036, 2013.

Harba, P. and Pilecki, Z.: Assessment of time-spatial changes of shear wave velocities of flysch formation prone to mass movements by seismic interferometry with the use of ambient noise, Landslides, 14, 1225-1233, https://doi.org/10.1007/s10346-0160779-2, 2017.

Harp, E. L., Reid, M. E., Godt, J. W., DeGraff, J. V., and Gallegos, A. J.: Ferguson rock slide buries California State Highway near Yosemite National Park, Landslides, 5, 331-337, https://doi.org/10.1007/s10346-008-0120-9, 2008.

Hartzell, S., Leeds, A. L., and Jibson, R. W.: Seismic Response of Soft Deposits due to Landslide: The Mission Peak, California, LandslideSeismic Response of Soft Deposits due to Landslide: The Mission Peak, California, Landslide, B. Seismo. Soc. Am., 107, 2008-2020, https://doi.org/10.1785/0120170033, 2017.
Hawthorne, J. and Ampuero, J.-P.: A phase coherence approach to identifying co-located earthquakes and tremor, Geophys. J. Int., 209, 623-642, https://doi.org/10.1093/gji/ggx012, 2017.

Helmstetter, A. and Garambois, S.: Seismic monitoring of Séchilienne rockslide (French Alps): Analysis of seismic signals and their correlation with rainfalls, J. Geophys. Res., 115, f03016, https://doi.org/10.1029/2009JF001532, 2010.

Helmstetter, A. and Janex, G.: Ecoute sismique et acoustique du mouvement de terrain de Séchilienne (Massif de Belledonne), Métrologie en Milieu Extrême, Collection EDYTEM, 2017.

Helmstetter, A., Ménard, G., Hantz, D., Lacroix, P., Thouvenot, F., and Grasso, J.-R.: Etude multidisciplinaire d'un effondrement dans la carrière de ciment de Saint-Martin-le-Vinoux, Journées Aléas Gravitaires, Strasbourg, France, 2011.

Helmstetter, A., Moreau, L., Nicolas, B., Comon, P., and Gay, M.: Intermediate-depth icequakes and harmonic tremor in an Alpine glacier (Glacier d'Argentière, France): Evidence for hydraulic fracturing?, J. Geophys. Res., 120, 402-416, https://doi.org/10.1002/2014JF003289, 2015a.

Helmstetter, A., Nicolas, B., Comon, P., and Gay, M.: Basal icequakes recorded beneath an Alpine glacier (Glacier d'Argentière, Mont Blanc, France): Evidence for stick-slip motion?, J. Geophys. Res., 120, 379-401, https://doi.org/10.1002/2014JF003288, 2015 b.

Helmstetter, A., Larose, E., Baillet, L., and Mayoraz, R.: Repeating quakes detected at Gugla rock-glacier and Alestch rockslide (Valais), 2017a.

Helmstetter, A., Larose, E., Baillet, L., and Mayoraz, R.: Repeating quakes detected at Gugla rock-glacier and Alestch rockslide (Valais), Enviroseis, From process to signal - advancing environmental seismology, Ohlstadt, Germany, 2017b.

Hencher, S. R.: Preferential flow paths through soil and rock and their association with landslides, Hydrol. Proc., 24, 1610-1630, https://doi.org/10.1002/hyp.7721, 2010.

Hibert, C., Mangeney, A., Grandjean, G., and Shapiro, N. M.: Slope instabilities in Dolomieu crater, Réunion Island: From seismic signals to rockfall characteristics, J. Geophys. Res., 116, F04032, https://doi.org/10.1029/2011JF002038, 2011.

Hibert, C., Mangeney, A., Grandjean, G., Baillard, C., Rivet, D., Shapiro, N. M., Satriano, C., Maggi, A., Boissier, P., Ferrazzini, V., and Crawford, W.: Automated identification, location, and volume estimation of rockfalls at Piton de la Fournaise volcano, J. Geophys. Res., 119, 1082-1105, https://doi.org/10.1002/2013JF002970, 2014a.

Hibert, C., Malet, J.-P., Bourrier, F., Provost, F., Berger, F., Bornemann, P., Tardif, P., and Mermin, E.: Single-block rockfall dynamics inferred from seismic signal analysis, Earth Surf. Dynam., 5, 283-292, https://doi.org/10.5194/esurf-5-283-2017, 2017a.

Hibert, C., Mangeney, A., Grandjean, G., Peltier, A., DiMuro, A., Shapiro, N. M., Ferrazzini, V., Boissier, P., Durand, V., and Kowalski, P.: Spatio-temporal evolution of rockfall activity from 2007 to 2011 at the Piton de la Fournaise volcano inferred from seismic data, J. Vol. Geotherm. Res., 333-334, 36-52, https://doi.org/10.1016/j.jvolgeores.2017.01.007, 2017b.

Hibert, C., Provost, F., Malet, J.-P., Maggi, A., Stumpf, A., and Ferrazzini, V.: Automatic identification of rockfalls and volcanotectonic earthquakes at the Piton de la Fournaise volcano using a 
Random Forest algorithm, J. Vol. Geotherm. Res., 340, 130-142, https://doi.org/10.1016/j.jvolgeores.2017.04.015, 2017c.

Huang, C.-J., Yin, H.-Y., Chen, C.-Y., Yeh, C.-H., and Wang, C.-L.: Ground vibrations produced by rock motions and debris flows, J. Geophys. Res., 112, f02014, https://doi.org/10.1029/2005JF000437, 2007.

Hungr, O., Evans, S. G., Bovis, M. J., and Hutchinson, J. N.: A review of the classification of landslides of the flow type, Environ. Eng. Geosci., 7, 221, https://doi.org/10.2113/gseegeosci.7.3.221, 2001.

Hungr, O., Leroueil, S., and Picarelli, L.: The Varnes classification of landslide types, an update, Landslides, 11, 167-194, https://doi.org/10.1007/s10346-013-0436-y, 2014.

Hürlimann, M., Abancó, C., Moya, J., and Vilajosana, I.: Results and experiences gathered at the Rebaixader debris-flow monitoring site, Central Pyrenees, Spain, Landslides, 11, 939-953, https://doi.org/10.1007/s10346-013-0452-y, 2014.

Itakura, Y., Fujii, N., and Sawada, T.: Basic characteristics of ground vibration sensors for the detection of debris flow, Physics and Chemistry of the Earth, Part B: Hydrology, Oceans Atmos., 25, 717-720, 2000.

Joswig, M.: Nanoseismic monitoring fills the gap between microseismic network and passive seismic, First Break, 26, 117-124, 2008.

Kanamori, H., Given, J. W., and Lay, T.: Analysis of seismic body waves excited by the Mount St. Helens eruption of May 18, 1980, J. Geophys. Res., 89, 1856-1866, 1984.

Kean, J. W., Coe, J. A., Coviello, V., Smith, J. B., McCoy, S. W., and Arattano, M.: Estimating rates of debris flow entrainment from ground vibrations, Geophys. Res. Lett., 42, 6365-6372, https://doi.org/10.1002/2015GL064811.

Kishimura, K. and Izumi, K.: Seismic Signals Induced by Snow Avalanche Flow, Nat. Hazards, 15, 89-100, https://doi.org/10.1023/A:1007934815584, 1997.

Kogelnig, A., Hübl, J., Suriñach, E., Vilajosana, I., and McArdell, B. W.: Infrasound produced by debris flow: propagation and frequency content evolution, Nat. Hazards, 70, 1713-1733, 2014.

Kumagai, H., Palacios, P., Maeda, T., Castillo, D. B., and Nakano, M.: Seismic tracking of lahars using tremor signals, J. Volcanol. Geoth. Res., 183, 112-121, https://doi.org/10.1016/j.jvolgeores.2009.03.010, 2009.

Lacroix, P. and Helmstetter, A.: Location of seismic signals associated with microearthquakes and rockfalls on the Séchilienne landslide, French Alps, Bull. Seis. Soc. Am., 101, 341-353, 2011.

Lacroix, P., Grasso, J.-R., Roulle, J., Giraud, G., Goetz, D., Morin, S., and Helmstetter, A.: Monitoring of snow avalanches using a seismic array: Location, speed estimation, and relationships to meteorological variables, J. Geophys. Res., 117, F01034, https://doi.org/10.1029/2011JF002106, 2012.

Langer, H., Falsaperla, S., Powell, T., and Thompson, G.: Automatic classification and a-posteriori analysis of seismic event identification at Soufrière Hills volcano, Montserrat, J. Vol. Geotherm. Res., 153, 1-10, https://doi.org/10.1016/j.jvolgeores.2005.08.012, 2006.

Larose, E., Carrière, S., Voisin, C., Bottelin, P., Baillet, L., Guéguen, P., Walter, F., Jongmans, D., Guillier, B., Garambois, S., Gimbert, F., and Massey, C.: Environmental seismology: What can we learn on earth surface pro- cesses with ambient noise?, J. Appl. Geophys., 116, 62-74, https://doi.org/10.1016/j.jappgeo.2015.02.001, 2015.

Larose, E., Bontemps, N., Lacroix, P., and Maquerhua, E. T.: Landslide monitoring in southern Peru: SEG Geoscientists Without Borders ${ }^{\circledR}$ project, in: 2017 SEG International Exposition and Annual Meeting, Soc. Expl. Geophys., 2017.

Lawrence, W. S. and Williams, T. R.: Seismic Signals Associated with Avalanches, J. Glaciol., 17, 521-526, https://doi.org/10.3189/S0022143000013782, 1976.

Lavigne, F., Thouret, J.-C., Voight, B., Young, K., LaHusen, R., Marso, J., Suwa, H., Sumaryono, A., Sayudi, D., and Dejean, M.: Instrumental lahar monitoring at Merapi Volcano, Central Java, Indonesia, J. Volcanol. Geoth. Res., 100, 457-478, 2000.

Lenti, L., Martino, S., Paciello, A., Prestininzi, A., and Rivellino, S.: Seismometric Monitoring of Hypogeous Failures Due to Slope Deformations, 309-315, Springer Berlin Heidelberg, Berlin, Heidelberg, https://doi.org/10.1007/978-3-64231445-2_40, 2013.

Le Roy, G., Amitrano, D., and Helmstetter, A.: Multidisciplinary study of rockfalls in Chartreuse massif, in: Enviroseis, From process to signal - advancing environmental seismology, 6-9 June 2017, Ohlstadt, Germany, 2017.

Le Roy, G., Helmstetter, A., Amitrano, D., Guyoton, F., and RouxMallouf, R. L.: Seismic characterization of rock falls from detachment to propagation, in: EGU General Assembly, Vienna, Austria, 2018.

Leprettre, B. J. P., Navarre, J.-P., and Taillefer, A.: First results from a pre-operational system for automatic detection and recognition of seismic signals associated with avalanches, J. Glaciol., 42, 352-363, https://doi.org/10.3189/S0022143000004202, 1996.

Lévy, C., Baillet, L., Jongmans, D., Mourot, P., and Hantz, D.: Dynamic response of the Chamousset rock column (Western Alps, France), J. Geophys. Res., 115, F04043, https://doi.org/10.1029/2009JF001606, 2010.

Levy, C., Jongmans, D., and Baillet, L.: Analysis of seismic signals recorded on a prone-to-fall rock column (Vercors massif, French Alps), Geophys. J. Int., 186, 296-310, https://doi.org/10.1111/j.1365-246X.2011.05046.x, 2011.

Levy, C., Mangeney, A., Bonilla, F., Hibert, C., Calder, E. S., and Smith, P. J.: Friction weakening in granular flows deduced from seismic records at the Soufrière Hills Volcano, Montserrat, J. Geophys. Res., 120, 7536-7557, https://doi.org/10.1002/2015JB012151, 2015.

Lipovsky, B. P. and Dunham, E. M.: Tremor during ice-stream stick slip, The Cryosphere, 10, 385-399, https://doi.org/10.5194/tc10-385-2016, 2016.

Lockner, D., Byerlee, J., Kuksenko, V., Ponomarev, A., and Sidorin, A.: Quasi-static fault growth and shear fracture energy in granite, Nature, 350, 39-42, https://doi.org/10.1038/350039a0, 1991.

Lomax, A., Virieux, J., Volant, P., and Berge-Thierry, C.: Probabilistic Earthquake Location in 3D and Layered Models, 101-134, Springer Netherlands, https://doi.org/10.1007/978-94-015-95360_5, 2000.

Lomax, A., Michelini, A., and Curtis, A.: Earthquake Location, Direct, Global-Search Methods, 1-33, Springer New York, https://doi.org/10.1007/978-3-642-27737-5_150-2, 2009.

Lotti, A., Saccorotti, G., Fiaschi, A., Matassoni, L., Gigli, G., Pazzi, V., and Casagli, N.: Seismic Monitoring of a Rockslide: The Torgiovannetto Quarry (Central Apennines, Italy), in: Engineering 
Geology for Society and Territory - Volume 2, edited by: Lollino, G., Giordan, D., Crosta, G. B., Corominas, J., Azzam, R., Wasowski, J., and Sciarra, N., 1537-1540, Springer International Publishing, Cham, 2015.

Lube, G., Cronin, S. J., Manville, V., Procter, J. N., Cole, S. E., and Freundt, A.: Energy growth in laharic mass flows, Geology, 40, 475-478, https://doi.org/10.1130/G32818.1, 2012.

Maggi, A., Ferrazzini, V., Hibert, C., Beauducel, F., Boissier, P., and Amemoutou, A.: Implementation of a multistation approach for automated event classification at Piton de la Fournaise volcano, Seismol. Res. Lett., 88, 878-891, https://doi.org/10.1785/0220160189, 2017.

Mainsant, G., Larose, E., Brönnimann, C., Jongmans, D., Michoud, C., and Jaboyedoff, M.: Ambient seismic noise monitoring of a clay landslide: Toward failure prediction, J. Geophys. Res., 117, f01030, https://doi.org/10.1029/2011JF002159, 2012a.

Mainsant, G., Jongmans, D., Chambon, G., Larose, E., and Baillet, L.: Shear-wave velocity as an indicator for rheological changes in clay materials: Lessons from laboratory experiments, Geophys. Res. Lett., 39, 119301, https://doi.org/10.1029/2012GL053159, 2012b.

Manconi, A. and Coviello, V.: Evaluation of the Raspberry Shakes seismometers to monitor rock fall activity in alpine environments, in: EGU General Assembly, Vienna, Austria, 2018.

Marcial, S., Melosantos, A. A., Hadley, K. C., LaHusen, R. G., and Marso, J. N.: Instrumental lahar monitoring at Mount Pinatubo, Fire and mud: eruptions and lahars of Mount Pinatubo, Philippines, edited by: Newhall, C. G. and Punongbayan, R. S., Washington Press, Seattle, 1015-1022, 1996.

McCann, D. and Forster, A.: Reconnaissance geophysical methods in landslide investigations, Eng. Geol., 29, 59-78, https://doi.org/10.1016/0013-7952(90)90082-C, 1990.

Michlmayr, G., Cohen, D., and Or, D.: Sources and characteristics of acoustic emissions from mechanically stressed geologic granular media - A review, Earth-Sci. Rev., 112, 97-114, https://doi.org/10.1016/j.earscirev.2012.02.009, 2012.

Michlmayr, G., Chalari, A., Clarke, A., and Or, D.: Fiber-optic highresolution acoustic emission (AE) monitoring of slope failure, Landslides, 14, 1139-1146, https://doi.org/10.1007/s10346-0160776-5, 2017.

Mikesell, T. D., van Wijk, K., Haney, M. M., Bradford, J. H., Marshall, H. P., and Harper, J. T.: Monitoring glacier surface seismicity in time and space using Rayleigh waves, J. Geophys. Res., 117, f02020, https://doi.org/10.1029/2011JF002259, 2012.

Navratil, O., Liébault, F., Bellot, H., Theule, J., Travaglini, E., Ravanat, X., Ousset, F., Laigle, D., Segel, V., and Fiquet, M.: Highfrequency monitoring of debris flows in the French Alps, in: Proceedings of 12th interpraevent congress, Grenoble, 281-291, 2012.

Neuberg, J., Luckett, R., Baptie, B., and Olsen, K.: Models of tremor and low-frequency earthquake swarms on Montserrat, J. Vol. Geotherm. Res., 101, 83-104, https://doi.org/10.1016/S0377-0273(00)00169-4, 2000.

Norman, E. C., Rosser, N. J., Brain, M. J., Petley, D. N., and Lim, M.: Coastal cliff-top ground motions as proxies for environmental processes, J. Geophys. Res.-Ocean, 118, 6807-6823, https://doi.org/10.1002/2013JC008963, 2013.

Occhiena, C., Coviello, V., Arattano, M., Chiarle, M., Morra di Cella, U., Pirulli, M., Pogliotti, P., and Scavia, C.: Analysis of microseismic signals and temperature recordings for rock slope stability investigations in high mountain areas, Nat. Hazards Earth Syst. Sci., 12, 2283-2298, https://doi.org/10.5194/nhess12-2283-2012, 2012.

Palis, E., Lebourg, T., Tric, E., Malet, J.-P., and Vidal, M.: Longterm monitoring of a large deep-seated landslide (La Clapiere, South-East French Alps): initial study, Landslides, 14, 155-170, https://doi.org/10.1007/s10346-016-0705-7, 2017.

Paul Winberry, J., Anandakrishnan, S., Wiens, D. A., and Alley, R. B.: Nucleation and seismic tremor associated with the glacial earthquakes of Whillans Ice Stream, Antarctica, Geophys. Res. Lett., 40, 312-315, https://doi.org/10.1002/grl.50130, 2013.

Pierson, T. C.: Flow characteristics of large eruption-triggered debris flows at snow-clad volcanoes: constraints for debris-flow models, J. Vol. Geotherm. Res., 66, 283-294, https://doi.org/10.1016/0377-0273(94)00070-W, 1995.

Podolskiy, E. A. and Walter, F.: Cryoseismology, Rev. Geophys., 54, 708-758, https://doi.org/10.1002/2016RG000526, 2016RG000526, 2016.

Poli, P.: Creep and slip: Seismic precursors to the Nuugaatsiaq landslide (Greenland), Geophys. Res. Lett., 44, 8832-8836, https://doi.org/10.1002/2017GL075039, 2017.

Pratt, M. J., Winberry, J. P., Wiens, D. A., Anandakrishnan, S., and Alley, R. B.: Seismic and geodetic evidence for grounding-line control of Whillans Ice Stream stick-slip events, J. Geophys Res., 119, 333-348, https://doi.org/10.1002/2013JF002842, 2014.

Provost, F., Hibert, C., and Malet, J.-P.: Automatic classification of endogenous landslide seismicity using the Random Forest supervised classifier, Geophys. Res. Lett., 44, 113-120, https://doi.org/10.1002/2016GL070709, 2017a.

Provost, F., Malet, J.-P., Hibert, C., and Vergne, J.: Significance and interest of dense seismic arrays for understanding the mechanics of clayey landslides: a test case of 150 nodes at Super-Sauze landslide, in: EGU General Assembly Conference Abstracts, 19, 14097, 2017b.

Provost, F., Malet, J.-P., Gance, J., Helmstetter, A., and Doubre, C.: Automatic approach for increasing the location accuracy of slow-moving landslide endogenous seismicity: the APOLoc method, Geophys. J. Int., 215, 1455-1473, https://doi.org/10.1093/gji/ggy330, 2018.

Pérez-Guillén, C., Sovilla, B., Suriñach, E., Tapia, M., and Köhler, A.: Deducing avalanche size and flow regimes from seismic measurements, Cold Reg. Sci. Techn., 121, 25-41, https://doi.org/10.1016/j.coldregions.2015.10.004, 2016.

RESIF/OMIV: RESIF - Réseau Sismologique et géodésique Français / OMIV- French Multidisciplinary Observatory of Versant Instabilities, https://doi.org/10.15778/RESIF.MT, 2015.

Richards, K. S. and Reddy, K. R.: Critical appraisal of piping phenomena in earth dams, Bull. Eng. Geol. Environ., 66, 381-402, https://doi.org/10.1007/s10064-007-0095-0, 2007.

Roeoesli, C., Helmstetter, A., Walter, F., and Kissling, E.: Meltwater influences on deep stick-slip icequakes near the base of the Greenland Ice Sheet, J. Geophys. Res., 121, 223-240, https://doi.org/10.1002/2015JF003601, 2016a.

Roth, M., Dietrich, M., Blikra, L. H., and Lecomte, I.: Seismic Monitoring of the Unstable Rock Slope Site at aknes, Norway, 184 192, https://doi.org/10.4133/1.2923645, 2008. 
Rouse, C., Styles, P., and Wilson, S.: Microseismic emissions from flowslide-type movements in South Wales, Eng. Geol., 31, 91110, https://doi.org/10.1016/0013-7952(91)90059-T, 1991.

Ruano, A., Madureira, G., Barros, O., Khosravani, H., Ruano, M., and Ferreira, P.: Seismic detection using support vector machines, Neurocomputing, 135, 273-283, https://doi.org/10.1016/j.neucom.2013.12.020, 2014.

Sabot, F., Naaim, M., Granada, F., Suriñach, E., Planet, P., and Furdada, G.: Study of avalanche dynamics by seismic methods, image-processing techniques and numerical models, Ann. Glaciol., 26, 319-323, https://doi.org/10.3189/1998AoG26-1319-323, 1998.

Schimmel, A. and Hübl, J.: Automatic detection of debris flows and debris floods based on a combination of infrasound and seismic signals, Landslides, 13, 1181-1196, https://doi.org/10.1007/s10346-015-0640-z, 2016.

Schneider, D., Bartelt, P., Caplan-Auerbach, J., Christen, M., Huggel, C., and McArdell, B. W.: Insights into rock-ice avalanche dynamics by combined analysis of seismic recordings and a numerical avalanche model, J. Geophys. Res., 115, F04026, https://doi.org/10.1029/2010JF001734, 2010.

Scholz, C. H.: Earthquakes and friction laws, Nature, 391, 37-42, https://doi.org/10.1038/34097, 1998.

Schöpa, A., Chao, W.-A., Lipovsky, B. P., Hovius, N., White, R. S., Green, R. G., and Turowski, J. M.: Dynamics of the Askja caldera July 2014 landslide, Iceland, from seismic signal analysis: precursor, motion and aftermath, Earth Surf. Dynam., 6, 467485, https://doi.org/10.5194/esurf-6-467-2018, 2018.

Senfaute, G., Duperret, A., and Lawrence, J. A.: Micro-seismic precursory cracks prior to rock-fall on coastal chalk cliffs: a case study at Mesnil-Val, Normandie, NW France, Nat. Hazards Earth Syst. Sci., 9, 1625-1641, https://doi.org/10.5194/nhess-9-16252009, 2009.

Shelly, D. R., Beroza, G. C., Ide, S., and Nakamula, S.: Lowfrequency earthquakes in Shikoku, Japan, and their relationship to episodic tremor and slip, Nature, 442, 7099, 188, 2006.

Smith, A., Dixon, N., Meldrum, P., Haslam, E., and Chambers, J.: Acoustic emission monitoring of a soil slope: Comparisons with continuous deformation measurements, Gétech. Lett., 4, 255261, https://doi.org/10.1680/geolett.14.00053, 2014.

Smith, A., Dixon, N., and Fowmes, G. J.: Early detection of first-time slope failures using acoustic emission measurements: large-scale physical modelling, Géotechnique, 67, 138-152, https://doi.org/10.1680/jgeot.15.P.200, 2017.

Spillmann, T., Maurer, H., Green, A. G., Heincke, B., Willenberg, H., and Husen, S.: Microseismic investigation of an unstable mountain slope in the Swiss Alps, J. Geophys. Res., 112, b07301, https://doi.org/10.1029/2006JB004723, 2007.

Stumpf, A., Malet, J.-P., Kerle, N., Niethammer, U., and Rothmund, S.: Image-based mapping of surface fissures for the investigation of landslide dynamics, Geomorphology, 186, 12-27, https://doi.org/10.1016/j.geomorph.2012.12.010, 2013.

Suriñach, E., Furdada, G., Sabot, F., Biesca, B., and Vilaplana, J. M.: On the characterization of seismic signals generated by snow avalanches for monitoring purposes, Ann. Glaciol., 32, 268-274, https://doi.org/10.3189/172756401781819634, 2001.

Suriñach, E., Vilajosana, I., Khazaradze, G., Biescas, B., Furdada, G., and Vilaplana, J. M.: Seismic detection and characterization of landslides and other mass movements, Nat. Haz- ards Earth Syst. Sci., 5, 791-798, https://doi.org/10.5194/nhess5-791-2005, 2005.

Surin, E., Sabot, F., Furdada, G., Vilaplana, J., et al.: Study of seismic signals of artificially released snow avalanches for monitoring purposes, Physics and Chemistry of the Earth, Part B: Hydrology, Ocean Atmos., 25, 721-727, 2000.

Suwa, H., Okano, K., and Kanno, T.: Behavior of debris flows monitored on test slopes of Kamikamihorizawa Creek, Mount Yakedake, Japan, Int. J. Ero. Contr. Eng., 2, 33-45, 2009.

Tang, C., Li, L., Xu, N., and Ma, K.: Microseismic monitoring and numerical simulation on the stability of high-steep rock slopes in hydropower engineering, J. Rock Mech. Geotech. Eng., 7, 493508, https://doi.org/10.1016/j.jrmge.2015.06.010, 2015.

Tary, J.-B., Van der Baan, M., and Eaton, D. W.: Interpretation of resonance frequencies recorded during hydraulic fracturing treatments, J. Geophys. Res., 119, 1295-1315, https://doi.org/10.1002/2013JB010904, 2014a.

Tary, J.-B., Van der Baan, M., Sutherland, B., and Eaton, D. W.: Characteristics of fluid-induced resonances observed during microseismic monitoring, J. Geophys. Res., 119, 8207-8222, https://doi.org/10.1002/2014JB011263, 2014b.

Thomas, A. M., Beroza, G. C., and Shelly, D. R.: Constraints on the source parameters of low-frequency earthquakes on the San Andreas Fault, Geophys. Res. Lett., 43, 1464-1471, https://doi.org/10.1002/2015GL067173, 2016.

Tonnellier, A., Helmstetter, A., Malet, J.-P., Schmittbuhl, J., Corsini, A., and Joswig, M.: Seismic monitoring of soft-rock landslides: the Super-Sauze and Valoria case studies, Geophys. J. Int., 193, 1515-1536, 2013.

Vázquez, R., Suriñach, E., Capra, L., Arámbula-Mendoza, R., and Reyes-Dávila, G.: Seismic characterisation of lahars at Volcán de Colima, Mexico, Bull. Vol., 78, https://doi.org/10.1007/s00445016-1004-9, 2016.

Vilajosana, I., Suriñach, E., Abellán, A., Khazaradze, G., Garcia, D., and Llosa, J.: Rockfall induced seismic signals: case study in Montserrat, Catalonia, Nat. Hazards Earth Syst. Sci., 8, 805-812, https://doi.org/10.5194/nhess-8-805-2008, 2008.

Voisin, C., Garambois, S., Larose, E., and Massey, C.: Seismic noise correlations and monitoring of the Utiku (New-Zealand) landslide, in: EGU General Assembly Conference Abstracts, Vol. 15 of EGU General Assembly Conference Abstracts, EGU20135406-1, 2013.

Vouillamoz, N., Rothmund, S., and Joswig, M.: Characterizing the complexity of microseismic signals at slow-moving clay-rich debris slides: the Super-Sauze (southeastern France) and Pechgraben (Upper Austria) case studies, Earth Surf. Dynam., 6, 525550, https://doi.org/10.5194/esurf-6-525-2018, 2018.

Walter, M., Walser, M., and Joswig, M.: Mapping RainfallTriggered Slidequakes and Seismic Landslide-Volume Estimation at Heumoes SlopeAll rights reserved. No part of this periodical may be reproduced or transmitted in any form or by any means, electronic or mechanical, including photocopying, recording, or any information storage and retrieval system, without permission in writing from the publisher, Vadose Zone J., 10, 487-495, 2011.

Walter, F., Dalban Canassy, P., Husen, S., and Clinton, J. F.: Deep icequakes: What happens at the base of Alpine glaciers?, J. Geophys. Res., 118, 1720-1728, https://doi.org/10.1002/jgrf.20124, 2013a. 
Walter, F., Burtin, A., McArdell, B. W., Hovius, N., Weder, B., and Turowski, J. M.: Testing seismic amplitude source location for fast debris-flow detection at Illgraben, Switzerland, Nat. Hazards Earth Syst. Sci., 17, 939-955, https://doi.org/10.5194/nhess-17939-2017, 2017.

Walter, M., Arnhardt, C., and Joswig, M.: Seismic monitoring of rockfalls, slide quakes, and fissure development at the Super-Sauze mudslide, French Alps, Eng. Geol., 128, 12-22, https://doi.org/10.1016/j.enggeo.2011.11.002, 2012.

Walter, M., Gomberg, J., Schulz, W., Bodin, P., and Joswig, M.: Slidequake Generation versus Viscous Creep at Softrock-landslides: Synopsis of Three Different Scenarios at Slumgullion Landslide, Heumoes Slope, and SuperSauze Mudslide, J. Environ. Eng. Geophys., 18, 269-280, https://doi.org/10.2113/JEEG18.4.269, 2013b.

Winberry, J. P., Anandakrishnan, S., Wiens, D. A., Alley, R. B., and Christianson, K.: Dynamics of stick-slip motion, Whillans Ice Stream, Antarctica, Earth Planet. Sci. Lett., 305, 283-289, https://doi.org/10.1016/j.epsl.2011.02.052, 2011.

Worni, R., Huggel, C., Stoffel, M., and Pulgarín, B.: Challenges of modeling current very large lahars at Nevado del Huila Volcano, Colombia, B. Volcanol., 74, 309-324, https://doi.org/10.1007/s00445-011-0522-8, 2012.

Yamada, M., Mangeney, A., Matsushi, Y., and Moretti, L.: Estimation of dynamic friction of the Akatani landslide from seismic waveform inversion and numerical simulation, Geophys. J. Int., 206, 1479-1486, https://doi.org/10.1093/gji/ggw216, 2016 a.
Yamada, M., Mori, J., and Matsushi, Y.: Possible stick-slip behavior before the Rausu landslide inferred from repeating seismic events, Geophys. Res. Lett., 43, 9038-9044, https://doi.org/10.1002/2016GL069288, 2016b.

Yin, H., Huang, C., Chen, C., Fang, Y., Lee, B., and Chou, T.: The present development of debris flow monitoring technology in Taiwan'a case study presentation, in: 5th International Conference on Debris-Flow Hazards Mitigation: Mechanics, Prediction and Assessment, edited by: Genevois, R., Hamilton, D. L., and Prestininzi, A., Casa Editrice Universita La Sapienza, Roma, 623-631, 2011.

Zigone, D., Voisin, C., Larose, E., Renard, F., and Campillo, M.: Slip acceleration generates seismic tremor like signals in friction experiments, Geophys. Res. Lett., 38, 101315, https://doi.org/10.1029/2010GL045603, 2011.

Zimmer, V. L. and Sitar, N.: Detection and location of rock falls using seismic and infrasound sensors, Eng. Geol., 193, 49-60, 2015.

Zobin, V. M., Plascencia, I., Reyes, G., and Navarro, C.: The characteristics of seismic signals produced by lahars and pyroclastic flows: Volcán de Colima, México, J. Volcanol. Geoth. Res., 179, 157-167, 2009. 